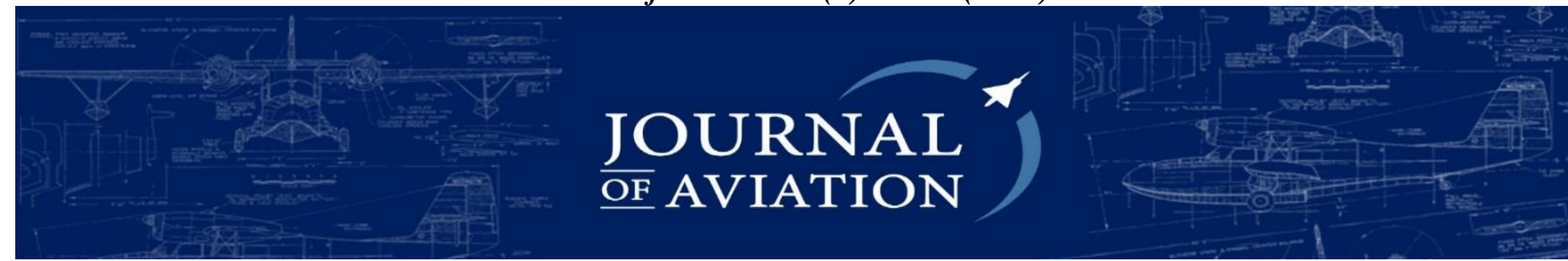

\title{
Hava Savunma Sanayii Alt Yüklenici Seçiminde Bulanık Mantık Altında Çok Kriterli Karar Verme Ve Hedef Programlama Yöntemlerinin Kullanılması
}

\author{
Yunus AYDIN 1 , Tamer EREN ${ }^{2 *}$ \\ ${ }^{1}$ TÜBİTAK/SAGE, Pk. 16 Mamak 06261 Ankara, Türkiye \\ ${ }^{2}$ Kırıkkale Üniversitesi, Mühendislik Fakültesi, Endüstri Mühendisliği Bölümü, KIRIKKALE
}

\section{Özet}

Tedarikçi seçimi ve değerlendirmesi tartışmasız bir organizasyonun başarısı için en kritik fonksiyonlardan biridir. Tedarikçi seçimlerini doğru yapan işletmeler pek çok alanda tasarruf sağlayıp, pazarda rekabet avantajı da elde etmektedirler. Doğru tedarikçi seçimi farklı firmalar için farklı anlamlar ifade edebilmekte, seçim yaparken kimi zaman sadece tek bir amaca yoğunlaşan işletmeler kimi zaman da birden çok amacı aynı anda eniyilemek istemektedirler. Bu çalışma, savunma sektöründe etkili tedarikçi seçimi ve sipariş verme süreçlerini mümkün kılan karar desteği için melez bir değerlendirme yaklaşımını sunmaktadır. Çalışmadaki entegre değerlendirme yöntemi bulanık AHP ve hedef programlama yaklaşımlarından oluşan iki aşamayı içermektedir. Tedarikçi değerlendirmesi ve seçimi hem nitel hem de nicel faktörleri içeren çok kriterli bir karar problemidir. Bundan dolayı çalışmada kalite, maliyet, tedarik süresi, insan gücü ve teknoloji kriterlerinin ağırlıklarını değerlendirmek için ilk olarak bulanık AHP yöntemi altında üçgen bulanık sayılarla ifade edilen dilsel değişkenler belirlenir. Daha sonra, bulanık küme teorisine dayalı bir hiyerarşi model kurularak ağırlıklar hesaplanmış olur. İkinci kısımda yani sırlamanın belirlenmesinde ise, kapasite kısıtı, üretim maliyet kısıtı, kaynağında kalite kontrol kısıtı, teslim süresi kısıtı, fire oranı kısıtı ve bulanık AHP öncelikleri kısıtlamaları ile oluşturulmuş bir hedef programlama modeli oluşturulur. Bulanık AHP'de elde edilen ağırlıklar hedef programlamada kısıt ve hedef olarak iki ayrı şekilde çözümlenmiştir.

Anahtar Kelimeler: Savunma Sanayi, Tedarikçi Seçimi Problemi, Bulanık AHP, Bulanık TOPSIS, Hedef Programlama

* Sorumlu Yazar/Corresponding Author: Doç. Dr. Tamer EREN tamereren@gmail.com
Alıntı/Citation : Aydın Y., Eren T. (2018). Hava Savunma Sanayi Alt Yüklenici Seçiminde Bulanık Mantık Altında Çok Kriterli Karar Verme Ve Hedef Programlama Yöntemlerinin Kullanılması. Journal of Aviation, 2 (1), 10-. DOI: 10.30518/jav.424231 


\title{
Multi Criteria Decision Making and Goal Programming Methods Using Fuzzy Logic in The Selection of Supplier in Air Defense Industries
}

\begin{abstract}
Supplier selection and evaluation is one of the most critical functions for an organization's success unequivocally. Businesses working with the appropriate suppliers pass on huge savings in many expense items and getting a competitive edge on the market. Selection of the most suitable supplier can mean different meanings for the firms. In other words, while some firms concentrate to a single objective for the supplier selection problem, some may aim to optimize the multiple objectives simultaneously. This study presents a hybrid assessment approach for decision support, which enables efficient supplier selection and ordering processes in the defense sector. The integrated evaluation methodology in the study includes two phases, which are fuzzy AHP and goal programming approaches. Supplier evaluation and selection is a multi-criteria decision-making problem involving both qualitative and quantitative factors. Therefore, in order to evaluate the weights of quality, cost, duration of supply, human power and technology criteria, linguistic variables expressed by triangular fuzzy numbers are determined under the fuzzy AHP method in the first phase. Then, a hierarchical model based on the fuzzy set theory is established and weights are calculated. For determination of suppliers ranking which is the second phase, a goal programming model is proposed with the capacity constraints, production cost constraints, resource quality constraints, delivery time constraints, fire rate constraints, and fuzzy AHP prioritization constraints.
\end{abstract}

Keywords: Defense Industry, Supplier Selection Problem, Fuzzy AHP, Goal Programing

\section{Giriş}

Tedarikçi seçimi, kalite, maliyet, teslimat, güvenilirlik vb. gibi birden fazla birbiriyle çelişen kriteri değerlendirmeyi gerektirir. Ayrıca, karar vericinin seçebileceği birden fazla alternatif olduğu da göz önüne alındığında, tedarikçi seçim kararı çok kriterli karar verme problemi olarak ele alınabilir. Literatürdeki çalışmalar incelendiğinde birçok tedarikçi seçim modelinin geliştirilmiş olduğu görülmektedir [1]. Bu kapsamda tedarikçi seçimi işletmelerin ihtiyaç duymuş oldukları ürün veya hizmetin kimden, ne kadar ve nasıl alınacağı konularının belirlenmesi olarak tanımlanabilir. Yapılacak olan işe uygun tedarikçilerin seçilmesi işletmeler açısından kalite, maliyet ve pazarda rekabet sağlamak adına önemli bir yere sahiptir.

Çalışmada kullanılan bulanık analitik hiyerarşi prosesi (BAHP) yöntemi bütün ölçütler için en iyi olanı belirleyen, sözel belirsizliği sayısal verilere dönüştüren ve en iyi alternatifi bu sayısal veriler 1şı̆̆ında belirleyen bir yaklaşımdır [2]. BAHP yönteminde ilk olarak üçgen bulanık sayılarla ifade edilen dilsel değişkenler belirlenir. Sonrasında bulanık küme teoresine göre ilgili hesapmalar yapılır ve sonuca gidilir. Çalışmada kullanılan diğer bir yöntem olan Hedef Programlama (HP) ise günümüzde yaygın olarak kullanılan çok ölçütlü karar verme tekniklerinden biridir. Hedef Programlamanın amacı birbiri ile çelişen çok sayıdaki hedefin arasından uygun sonuçlara ulaşabilmeyi sağlamaktır.

$\mathrm{Bu}$ çalıșmada ülkemizin önde gelen AR-GE kurumlarından olan TS firmasında üzerinde çalışılmakta olan füze sistemleri için mekanik bileşenlerin üretimi söz konusudur. Bu kapsamda bu bileşenlerin üretimi için tedarikçi seçim çalışmasının yapılması hedeflenmektedir. Yapılacak olan bu seçimin belirli kriterler altında yapılarak nihai sonuca ulaşılması beklenmektedir. $\mathrm{Bu}$ kriterler; kalite, maliyet, tedarik süresi, insan gücü ve teknoloji kriterleridir. Problemin çözülmesi için BAHP ve Hedef Programlama algoritmaları bir arada kullanılmıştır. 
Çalışmanın ikinci bölümünde, tedarikçi seçim problemi ile ilgili literatürdeki çalışmalar hakkında bilgi verilmiştir. $\mathrm{Bu}$ alanda yapılan çalışmalara kısaca değinilmiştir. Çalışmanın üçüncü bölümünde, tedarikçi seçim problemi ile ilgili tanımlar, en sık kullanılan kriterler hakkında bilgiler verilmiştir. Çalışmanın dördüncü bölümünde, problemin çözümünde kullanılacak olan Çok Kriterli Karar Verme (ÇKKV) yöntemlerinden olan BAHP yöntemi anlatılmış ve bulanık mantık hakkında kısa bir bilgi verilmiştir. Çalışmanın beşinci bölümünde, problemin çözümünde kullanılacak olan hedef programlama yöntemi ilgili parametreleri ile anlatılmıştır. Çalışmanın altıncı bölümünde, buraya kadar anlatılan yöntemler kullanılarak gerçek bir problemin uygulama kısmı anlatılmıştır. Problemin tanıtılması, verilerin toplanmas1, alternatiflerin belirlenmesi, kriterlerin belirlenmesi ve gerçek bir problem çözümü sunulmuştur. Çalışmanın son bölümü olan yedinci bölümünde, yapılan bu çalışmaların sonuçları hakkında detaylı bilgiler verilmiştir.

\section{Literatürde Yapılan Çalışmalar}

Tedarikçi seçimi ile ilgili literatürde yapılan bazı çalışmalar aşağıda belirtilmiştir;

Schniederjans vd. [3] bu makalede, ev seçimi karar sürecine yardımc1 olacak bir model sunulmaktadır. Özellikle bu yazı, mülkiyet özelliklerini değerlendirmek ve en uygun evi seçme kararı vermek için Analitik Hiyerarşi Süreci'ni kullanan bir Hedef Programlama modeli sunmaktadır. Ghodsypour ve O'Brien [4], bu makalede, analitik bir hiyerarşi sürecinin ve doğrusal programlamanın bütünleştirilmesi, en iyi tedarikçilerin seçiminde hem maddi hem de maddi olmayan faktörleri göz önünde bulundurmak ve aralarındaki optimum sipariş miktarlarını satın alma toplamının maksimuma çıkacağı şekilde yerleştirilmesi önerilmektedir. Badri [5], uluslararası bir ortamda konum tahsisi sorununun çoklu ve çakışan nesnel doğasını kabul eden bu makale, konum tahsisi kararları vermede yardımc1 olarak Analitik Hiyerarşi Süreci ve çok amaçlı hedef programlama metodolojisini kullanmay önermektedir. Dağdeviren ve Eren [6], tedarikçi seçiminde AHP ve Hedef Programlama yöntemlerinin birlikte kullanılması araştırılmıştır.
Kağnıcioğlu [7], bu çalışmada, hedef programlama ve bulanık hedef programlama tanitıldiktan sonra hem sayısal bir örnek model hem de ana üretim planlaması ile ilgili bir örnek model hedef programlama ve bulanik hedef programlama ile çözümlenmiştir. Reddy vd. [8], bu makalede, yazılım mimarisi seçimi için AHP ve Hedef programlamanın bütünsel bir yaklaşımı olarak adlandırılan çok amaçlı fonksiyonlarla başa çıkmak için bir çerçeve çalışması önerilmektedir. Öztürk vd. [9], bu çalışmada, işletmelerin karar problemlerinde karar vericiler tarafindan yapılan sözel değerlendirmelerde yer alan belirsizliği ele alabilmek için BAHP ve Bulanık TOPSIS (BTOPSIS) yöntemleri önerilmiştir. Girginer ve Kaygısız [10], bu çalışmada; ele alınan bir üniversitede gerek akademisyenlerin akademik çalışmalarında gerekse eğitimde kullanılacak olan en uygun istatistiksel yazılımın belirlenmesinde, Analitik Hiyerarşi Süreci (AHS) ve 0-1 Hedef Programlama (HP) yöntemleri birlikte kullanılmıştır. Aktepe ve Ersöz [11], tedarikçi seçimi için bir BAHP modeli ve bir vaka çalışması yapmışlardır. Kazançoğlu ve Ada [12], bu çalışmada BAHP ile perakende sektöründe tedarikçi seçimi çalışması yapılmıştır. Karpak vd. [13], bu çalışmada, görsel etkileşimli hedef programlama ile tedarikçi seçim çalışması yapılmıştır. [1] bu çalışmada, makine sektöründe faaliyet gösteren bir işletme için tedarikçi seçim problemi ele alınmıştır. Doğru tedarikçi seçimi için birçok nitel ve nicel kriterin birlikte dikkate alınması gerektiğinden, tedarikçi seçimi için çok kriterli karar verme tekniklerinden Analitik A $\breve{g}$ Süreci (ANP) ve ELECTRE yöntemleri bütünleşik bir şekilde uygulanmıştır. Junior vd. [14], bu çalışmada, BAHP ve BTOPSIS yöntemlerinin tedarikçi seçimi ile karşılaştırılması yapılmıştır. Karimi ve Rezaeinia [15], tedarikçi seçimi, bu makalede incelenen karar verme açısından çok önemli kriterlerden biridir. $\mathrm{Bu}$ araştırma, hedef programlamadaki farklı pozisyonları göz önüne alan çok parçalı hedef programlama formülasyonu uygular. Kannan vd. [16], çalışmalarında Brezilya'da bir elektronik firması için BTOPSIS yöntemi ile tedarikçi seçimi yapılmıştır. Özder vd. [17], bu çalışmada otomotiv sektöründe faaliyet gösteren bir firmanın tedarikçi seçim problemi ele alınmıştır. Problemi çözmek için 
hedef programlama tekniği kullanılmıştır. Kar [18], çalışmada tedarikçi seçim problemi için bulanık küme teorisi, AHP ve yapay sinir ağları metotlarından oluşan melez bir yöntem önermişlerdir. Jadidi vd. [19], bu çalışmada, yeni birçok seçenekli hedef programlama (MCGP) yaklaşımı önerilmiştir. Önerilen modelin en önemli avantajlarından biri, karar vericilere tercihleri üzerinde daha fazla kontrol sahibi olmasını sağlamak ve örnekleyici bir örnek ile önerilen modelin etkinliğini göstermektir. Sivrikaya [20], bu çalışmada, tekstil endüstrisinde etkili bir tedarikçi seçimi ve sipariş verme süreci sağlayan karar destek için entegre bir değerlendirme yaklaşımı sunulmaktadır. Galankashi vd. [21], çalışmalarında otomotiv sektöründe tedarikçileri değerlendirme ve seçmek için BAHP modeli önerilmiştir. Özder ve Eren [22], bu çalışmada, otomotiv üretiminde faaliyet gösteren tedarikçi seçimi sorunu tartışılmıştır. Sorunu çözmek için öncelikli hedef programlama kullanılmış ve ideal çözüm noktalarını belirlemek için ise TOPSIS yöntemleri kullanılmıştır. Tavana vd. [23], çalışmalarında yöneticilere tedarikçilerin değerlendirme sürecinde yardımcı olması için melez bir uyarlamalı sinir bulanık çıkarım sistemi -Yapay Sinir A Ăı modeli önerilmiştir. AHP aracılığıyla veri setini topladıktan sonra, tedarikçilerin performansı üzerindeki en etkili kriterler uyarlamalı sinir bulanık çıkarım sistemi tarafından belirlenir. Ardından, tedarikçilerin performansını en etkili ölçütlere dayalı olarak öngörmek ve derecelendirmek için Çok Katmanlı Algılayıcı kullanılır. Ayrıca örnek bir vaka çalışması yapılmıştır. Aydın ve Eren [24], çalışmalarında savunma sanayinde geliştirilmekte olan füze sistemlerinde kullanılan mekanik parçaların üretimi için seçilen kriterlere göre en iyi tedarikçiyi belirleyen hibrit bir yöntem (BAHP-HP) üzerinde durulmuş; kalite, maliyet, tedarik süresi, insan gücü ve teknoloji kriterleri doğrultusunda bir seçim yapılmaya çalışılmıştır. Aydın ve Eren [25], çalışmalarında savunma sanayinde geliştirilmekte olan füze sistemleri için kritik ham malzeme sınıfında olan parçaların üretimi için en iyi tedarikçinin seçilmesi maksadıyla, seçilen kriterlere göre en iyi tedarikçiyi belirleyen bir BAHPBTOPSIS melez yöntemi üzerinde durulmuş; kalite, fiyat uygunluğu, teslim süresi, uygun makine ve yaşanılmış tecrübe kriterleri doğrultusunda bir seçim yapılmaya çalışılmıştır. Aydın ve Eren [26], çalışmalarında savunma sanayinde kritik bir alt bileşen için en iyi tedarikçinin seçilmesi maksadıyla, seçilen kriterlere göre en iyi tedarikçi belirleyen bir AHP-TOPSIS melez yöntemi üzerinde durulmuş; kalite, maliyet, teslimat, makina parkuru, kalifiye işçilik ve teknik yeterlilik kriterleri doğrultusunda bir seçim yapılmaya çalışılmıştır.

Yapılan bu çalışmada literatürde yapılan çalışmalardan farklı olarak gerçek bir problem incelenmiş, işletme bünyesinde manuel olarak sürdürülmekte olan tedarikçi seçim çalışmaları bilimsel bir çalışma altında yapılacağının bilinci uyandırılmış olup gerekli alt yapı çalışmalarının oluşturulmasına müteakip çok kriterli karar verme yöntemleri ile daha sistemli bir şekilde yapılacağ 1 vurgulanmıştır.

\section{Tedarikçi Seçim Problemi}

Tedarikçi seçimi, firmaların tedarikçileri tanımlama, değerlendirme ve sözleşme yapma sürecidir. Tedarikçi seçim süreci, bir firmanın finansal kaynaklarının muazzam miktarda dağılımını sağlar. Buna karşılık, firmalar, yüksek değer sunan tedarikçilerle sözleşme yapmaktan önemli fayda beklerler [27].

Tedarikçiler her zaman bir şirketin yönetim politikasının ayrılmaz bir parçası olmuştur; Bununla birlikte, şirketler ve tedarikçileri arasındaki ilişki geleneksel olarak uzak olmuştur. Günümüzde tam zamanında üretim (TZÜ) ve katma değer odaklı küresel ekonomide, bu tuhaf ilişkiyi, iş birliği ve kesintisiz entegrasyondan birine dönüştürmek kaçınılmaz hale gelmiş bulunmaktadır. TZÜ, satıcının belirli bir sürede malzemenin kesin talep edilen miktarını istenilen kalite, maliyet ve zamanında üretmesini ve teslim etmesini gerektirir. Dolayısıyla tedarikçinin performansı bir şirketin başarısı veya başarısızlığının önemli bir unsuru haline gelir. Düşük maliyetli, yüksek kalite, esneklik ve hızlı tepki hedeflerine ulaşmak için şirketler giderek daha iyi tedarikçi seçimi yaklaşımlarını düşünmektedir [28].

$\mathrm{Bu}$ yaklaşımlar, paylaşım masrafları, faydaları, uzmanlık alanlarında iş birliği yapmayı ve karşılıklı olarak tedarik, tedarikçi ve uzun vadeli ortaklıklar 
oluşturan birbirinin güçlü ve zayıf yönlerini anlamaya çalışmaktadır [29].

Bununla birlikte, bu ortakl1kları geliştirmek çok fazla çalışma ve sabır gerektirir. Tedarikçi seçme süreci şirket içinde farklı işlevleri (satın alma, kalite, üretim vb.) kapsadığı için hiyerarşik olarak birçok maddi ve manevi unsuru içine alan çok amaçlı bir sorundur. Somut olmayan faktörlerin değerlendirilmesi uzman değerlendirmesini gerektirir ve hiyerarşik yapı bu faktörlerin parçalanmasını ve sentezini gerektirir.

Tarihsel olarak, alıcılar ve tedarikçiler arasında genellikle karşıt bir ilişki vardır. Bununla birlikte, son birkaç yılda bu ilişkide olumlu bir değişim gözlemlenmiştir. Kısa ömürlü ürün ömrü, artan teknolojik değişim oranları ve yabancı kaynak temini gibi eğilimler, alıcılar ve tedarikçiler arasında iletişim ve iş birliğinin geliştirilmesini ve tek kaynak alımları gibi yönetim uygulamalarına etkileri geliştirmiştir. Tedarikçi seçimi genellikle uzun bir değerlendirme sürecidir. Tedarikçiler maliyet, teslimat, kalite ve hizmet gibi çeşitli kriterlere göre değerlendirilir.

Sıklıkla, bu değerlendirme kriterleri birbiriyle örtüşmeleri içerir. Örneğin, bir tedarikçi ortalama kalitesinin biraz altındaki ucuz parçaları sunabilirken, başka bir tedarikçi belirsiz teslimat ile daha kaliteli parçalar sunabilir, böylece dengeleme kurabilir. Bununla birlikte, her kriterin önemi bir satın alımdan diğerine değişir ve bazı ölçütlerin niceliksel (fiyat, kalite, vb.) olması, diğerlerinin nitel (hizmet, esneklik, vb.) olması nedeniyle daha da karmaşıktır. Bu nedenle, karar vericinin her kriterin önemine yönelik tutumunu ayarlayabilen ve hem nitel hem de nicel faktörleri içeren bir teknik gereklidir. Çoğu alıcı, maliyeti birincil kaygısı olarak görürken, yeni interaktif ve birbirine bağımlı seçim kriterleri giderek daha fazla kullanılmaktadır [30].

İşletmelerde bir satın alma bölümünün hedefi, mümkün olan en iyi müşteri hizmetleri ve desteği ile en düşük toplam maliyet, en kaliteli ürünleri ve hizmetleri zamanında sağlamak olmalıdır.

\section{4. Çok Kriterli Karar Verme Yöntemleri}

Bireyler, işletmeler ve/veya organizasyonlar yaşamın her alanında çok boyutlu karar problemleri ile karşılaşmaktadır. Yöneticiler çoğu zaman, birden fazla faktörün ve birbirleriyle çatışan amaçların (kriterlerin) gerçekleştirilmek istendiği durumlarda karar vermektedirler. Çok kriterli karar verme teknikleri, birbiri ile çatışan birden fazla kriteri karşılayan olası "en iyi/uygun" çözüme ulaşmaya çalışan yaklaşım ve yöntemlerden oluşmaktadır. Karar vericiler, bu tür problemlerin üstesinden gelmede çok kriterli karar verme tekniklerinden faydalanarak bilimsel ve daha başarılı kararlar verebilirler.

Çok kriterli karar verme yaklaşımlarında belirgin sayıda ve özellikteki aday, plan, politika, strateji, hareket biçimi alternatifleri karşılaştırılarak derecelendirilir ve bunların arasından en iyisi seçilmeye çalışlır. Çok kriterli karar verme yöntemleri kriterlere ilişkin ağırlık bilgisini kullanarak, çatışan niteliklere sahip karmaşı problemlerin çözülmesini sağlarlar. İlk olarak alternatiflerin ve niteliklerin tanımlaması yapılır. Sonrasinda her bir alternatifin (ayr1 ayr1), her kritere göre ölçümleri elde edilir, kriterlere göre ağırlıkları atanır. Atanan kriter ağırlıkları ve alternatiflerin tekkriterli değer ölçümleri -bir bütüncülleştirme modeli ile- bir araya getirilerek alternatiflerin bütünsel (overall) değerleri saptanır. Son olarak duyarlılık analizleri gerçekleştirilir ve sonuç önerileri ile değerlendirmeleri ortaya konulur [31].

Uygulamada yaygın olarak kullanılan yöntemlerden BAHP yöntemi ve hedef programlama yöntemleri ele alınmıştır.

\subsection{Bulanık Mantık}

Bulanık mantık Lotfi Zadeh tarafindan 1965 yılında literatüre kazandırılmıştır. Bulanık mantık ilkeleri belirsizliği açıklama kabiliyeti açısından üstünlüğü ile öne çıkmaktadır. Teori, matematiksel işlemleri ve programlamayı bulanık alanda uygulamaya da elverişlidir. Bir bulanık küme, her bir elemanı 0 ile 1 arasında değişen üyelik derecesine sahip bir fonksiyon ile tanımlanır. $\mathrm{Bu}$ üyelik dereceleri, bir bulanık küme için süreklilik arz eder [32].

Bulanık mantık, belirsizlik ve kesin olmayan gerçek problemlerin tanımlanması ve çözülmesi için kullanışlı bir tekniktir. Bulanık mantık "evet" ya da "hayır", "doğru" ya da "yanlış" gibi klasik değişkenler yerine "orta", "yüksek", "düşük" gibi ortalama değerleri kullanan çok değişkenli bir teoridir [33]. 


\subsection{Bulanık Analitik Hiyerarşi Prosesi}

BAHP yöntemi Zadeh [34] tarafindan ortaya konulan bulanık küme teorisi yaklaşımına dayanmaktadır [34]. Bulanıklığın söz konusu olduğu durumda hiyerarşik yapıların analizi ilk olarak karar vericilerin ikili karşılaştırmalara ilişkin ifadelerini incelerken kesin değerler yerine bulanık oranlardan faydalanmış olan Buckley [35] tarafından önerilmiştir.

BAHP sayesinde karar vericiler ikişerli karşılaştırmalar yaparken "İyi", "Daha iyi" gibi ifadeleri kullanarak değerlendirme yapabilmektedir. $\mathrm{Bu}$ da karar vericilerin değerlendirme yapmalarını oldukça kolaylaştırmaktadır.

Tedarikçilerin BAHP ile değerlendirilmesinde kullanılan metodolojiyi aşağıdaki şekilde maddeleyebiliriz;

- Uzman heyetinin kriterleri belirlemesi,

- Kriterler ve Alternatiflerin önem skalası ve bu değerlere karşılık gelen bulanık sayılar ile değerlendirilmesi (Tablo 1.),

Tablo 1. Chang yöntemine göre BAHP'de kullanılan ölçek

\begin{tabular}{l|ll}
\multicolumn{1}{|c|}{ Sözel Önem } & $\begin{array}{c}\text { Bulanık } \\
\text { Ölçek }\end{array}$ & $\begin{array}{c}\text { Karşılık } \\
\text { Ölçek }\end{array}$ \\
\hline Eşit önemli & $(1,1,1)$ & $(1 / 1,1 / 1,1 / 1)$ \\
$\begin{array}{l}\text { Biraz daha fazla } \\
\text { önemli }\end{array}$ & $(1,3,5)$ & $(1 / 5,1 / 3,1 / 1)$ \\
$\begin{array}{l}\text { Kuvvetli } \\
\text { derecede önemli }\end{array}$ & $(3,5,7)$ & $(1 / 7,1 / 5,1 / 3)$ \\
$\begin{array}{l}\text { Çok kuvvetli } \\
\text { derecede önemli }\end{array}$ & $(5,7,9)$ & $(1 / 9,1 / 7,1 / 5)$ \\
$\begin{array}{l}\text { Tamamıyla } \\
\text { önemli }\end{array}$ & $(7,9,9)$ & $(1 / 9,1 / 9,1 / 7)$ \\
\end{tabular}

Karş1laştırmalar, formül (4.1)'de görüldüğü gibi ikili karşılaştırma matrisinin tüm değerleri (1) olan köşegeninin üstünde kalan değerler için yapılmaktadır. $a_{i j}$ bulanık sayısı, $i$. eleman ile $j$. elemanın ikili karşılaştırma değeri olarak gösterilecek olursa, $a_{i j}$ bulanık sayı değeri $1 / a_{i j}$ eşitliğinden elde edilir. [36].

$$
\tilde{A}=\left[\tilde{a}_{i j}\right]=\left[\begin{array}{cccc}
1 & \tilde{a}_{12} & \cdots & \tilde{a}_{1 n} \\
\frac{1}{\tilde{a}_{12}} & 1 & \cdots & \tilde{a}_{2 n} \\
\vdots & \vdots & \vdots & \vdots \\
\frac{1}{\tilde{a}_{1 n}} & \frac{1}{\tilde{a}_{2 n}} & \cdots & 1
\end{array}\right]
$$

- Kriterler ve Alternatiflerin bulanık önem ağırlıklarının hesaplanması.

BAHP çalışmalarında en çok karşılaşılan çözüm yöntemi ise Chang tarafindan 1996 y1lında önerilen Genişletilmiş Analiz Yöntemidir. BAHP'nin ikili karşılaştırma skalası için üçgensel bulanık sayıların kullanılması ve ikili karşılaştırmaların sentetik derece değerleri için derece analiz yönteminin kullanılmasını içeren yeni bir yaklaşım ortaya koymaktadir.

$\mathrm{Bu}$ metot, Chang [37] tarafindan yazılan "Application of the Extent Analysis Method on Fuzzy AHP" isimli makaleye dayanmaktadır. AHP ile birlikte üçgensel bulanık sayıları karşılaştırmak için geliştirilen bir metottur. Çok kullanışlı ve kolay uygulanabilir bir yöntemdir.

Bu çalışmada Genişletilmiş BAHP yöntemi ele alınmıştır. Genişletilmiş BAHP yöntemi, insani düşünce tarzının belirsizliğini ele alma yeteneğine sahiptir ve çok kriterli karar verme problemlerini çözmede etkilidir. Bu yöntemde izlenen metodoloji şu şekilde açıklanabilir:

$\mathrm{X}=\left\{\mathrm{X}_{1}, \mathrm{X}_{2}, \ldots, \mathrm{X}_{\mathrm{n}}\right\}$ bir nesneler kümesi ve $\mathrm{U}=\left\{\mathrm{u}_{1}, \mathrm{u}_{2}, \ldots, \mathrm{u}_{\mathrm{n}}\right\}$ de bir amaçlar kümesi olsun. Genişletilmiş analiz yöntemine göre, her bir nesne bir amacı gerçekleştirmek için ele alınır. Genişletilmiş ifadesi ile bu nesnenin amacı ne kadar gerçekleştirdiği ifade edilmektedir. Böylece, $\mathrm{m}$ tane genişletilmiş analiz değeri elde edilmiş olup, Denklem (4.2)'deki gibi gösterilir.

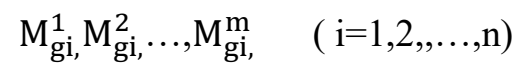

Buradaki tüm $\mathrm{M}_{g i}^{\mathrm{i}}(\mathrm{j}=1,2, \ldots, \ldots)$ değerleri, üçgen bulanık sayılardır. Change'in genişletilmiş analizinin adımları aşağıdaki gibi özetlenebilir [32].

Adım1: i. Nesne için bulanık büyüklük değeri şu şekilde tanımlanır;

$\mathrm{S}_{\mathrm{i}}=\sum_{\mathrm{j}=1}^{\mathrm{m}} \mathrm{M}_{\mathrm{gi}}^{\mathrm{i}} \mathrm{x}\left[\sum_{\mathrm{i}=1}^{\mathrm{n}} \sum_{\mathrm{j}=1}^{\mathrm{m}} \mathrm{M}_{\mathrm{gi}}^{\mathrm{i}}\right]^{-1}$

$\mathrm{S}_{\mathrm{i}}=\mathrm{i}$. Amacin sentez değeri

$\mathrm{M}_{\mathrm{gi}}^{\mathrm{i}}=$ Herbir amaca yönelik genişletilmiş değer

$$
\begin{aligned}
& \sum_{\mathrm{j}=1}^{\mathrm{m}} \mathrm{M}_{\mathrm{gi}}^{\mathrm{i}}=\left(\sum_{\mathrm{j}=1}^{\mathrm{n}} \mathrm{l}_{\mathrm{j}}, \sum_{\mathrm{j}=1}^{\mathrm{n}} \mathrm{m}_{\mathrm{j}}, \sum_{\mathrm{i}=1}^{\mathrm{n}} \mathrm{u}_{\mathrm{j}}\right) \\
& {\left[\sum_{\mathrm{i}=1}^{\mathrm{n}} \sum_{\mathrm{j}=1}^{\mathrm{m}} \mathrm{M}_{\mathrm{gi}}^{\mathrm{i}}\right]^{-1}=\left(\frac{1}{\sum_{\mathrm{i}=1}^{\mathrm{n}} \mathrm{u}}, \frac{1}{\sum_{\mathrm{i}=1}^{\mathrm{n}} \mathrm{m}}, \frac{1}{\sum_{\mathrm{i}=1}^{\mathrm{n}} \mathrm{l}_{\mathrm{j}}}\right)}
\end{aligned}
$$


Adım2: Bulanık değerler hesaplandıktan sonra, bu değerler birbirleriyle karşılaştırılarak, seçeneklerin ve ölçütlerin olabilirlik değerleri V elde edilir.

$$
\left\{\begin{array}{cc}
\mathrm{V}\left(\tilde{\mathrm{M}_{2}} \geq \tilde{\mathrm{M}_{1}}\right)= & \text { ĕger } \mathrm{m}_{2} \geq \mathrm{m}_{1} \\
0, & \text { eğer } \mathrm{l}_{1} \geq \mathrm{u}_{2} \\
\frac{\mathrm{l}^{1}-\mathrm{u}_{2}}{\left(\mathrm{~m}_{2}-\mathrm{u}_{2}\right)-\left(\mathrm{m}_{1}-\mathrm{l}_{1}\right)} & \text { diğer durumda }
\end{array}\right.
$$

Adım3: Konveks bir bulanık sayının k adet bulanık sayıdan, $M_{i}(i=1,2, \ldots, k)$ daha büyük olabilirlik derecesi şu şekilde tanımlanır;

$$
\begin{gathered}
V\left(M \geq M_{1}, M_{2}, \ldots M_{k}\right)=\left[\left(M \geq M_{1}\right) \text { ve } \ldots(M \geq\right. \\
\left.\left.M_{k}\right)\right]=\min V\left(M \geq M_{i}\right), i=1,2,3, \ldots, k \\
S_{j} \text { ler için şu varsayımlar yapılmıştır; } \\
k=1,2,3, \ldots, n k \neq j \text { için } d^{\prime}\left(A_{i}\right)=\operatorname{minV}\left(S_{i} \geq S_{k}\right)
\end{gathered}
$$

Daha sonra Ağırlık Vektörü Ai (i = $1,2,3, \ldots, n)$ 'nin $n$ elemandan oluştuğu şu şekilde ifade edilir;

$$
W^{\prime}=\left(d\left(A_{1}\right), d\left(A_{2}\right), d\left(A_{3}\right), \ldots, d\left(A_{n}\right)\right)^{T}
$$

Adım4: Normalizasyon ile normalize edilmiş ağırlık vektörü $\mathrm{W}$ elde edilir ve burada $\mathrm{W}$ bir bulanık sayı değildir. Normalizasyon işlemi 4.9'daki herbir değeri yine o değerlerin toplamına bölünmesi ile elde edilir.

$$
W=\left(d\left(A_{1}\right), d\left(A_{2}\right), d\left(A_{3}\right), \ldots, d\left(A_{n}\right)\right)^{T}
$$

\section{Hedef Programlama}

Hedef programlama (HP), matematiksel bir programlama optimizasyon metodolojisidir. HP modeli, bir dizi hedeflenen hedef seti ile optimal bir çözüm üretmek üzere tasarlanmıştır. Bütün HP modelleri, bilinmeyenler, parametreler, bir amaç fonksiyonu ve hedef kısıtlarından oluşmaktadır.

Hedef Programlamanın ilk çıkışı, 1955 yılında Charnes ve arkadaşları tarafindan yapılan çalışmaya dayanır [38]. Gerçek hayata uygulanabilirliği bakımından çok etkin bir teknik olan HP günümüzde üretim planlaması iş gücü planlamas1, akademik kaynak tahsisi, finansal planlama, bütçeleme, nakliye, performans tahmin gibi birçok alanda en yaygın şekilde kullanılan çok kriterli karar verme tekniklerinden biri haline gelmiştir [10].

Yöntemin Algoritması verilen bilgiler çerçevesinde adım adım aşağıdaki şekilde özetlenebilir: [39].

- Sorun basit bir Lineer Program modeli olarak formüle edilir,
- Her bir hedef için sapma değişkenleri tanımlanır,

- Hedef programlama ve sistem kisitlamaları yazılır,

- Fonksiyonel ve sapma değişkenleri için negatif olmayan kisitlamalar eklenir,

- Amaç fonksiyonunda küçültülecek değişkenler belirlenir,

- Amaçlarla öncelikleri yazılır.

Program aşağıdaki şekilde formüle edilir:

Değişkenler;

$x_{j}: j$. Karar değişkeni

$\mathrm{a}_{\mathrm{ij}}$ : i. hedefin $\mathrm{j}$. karar değişkeni katsayısı

$b_{i}: i$. hedef için ulaşılmak istenen değer

$\mathrm{d}_{\mathrm{i}}^{+}: \mathrm{i}$. hedefin pozitif sapma değişkeni

$\mathrm{d}_{\mathrm{i}}{ }^{-}: \mathrm{i}$. hedefin negatif sapma değişkeni

Genel gösterim ise şu şekildedir [34].

Minimize $\mathrm{Z}=\sum_{\mathrm{i}=1}^{\mathrm{m}}\left(\mathrm{d}_{\mathrm{i}}^{+}+\mathrm{d}_{\mathrm{i}}^{-}\right)$

$\sum_{\mathrm{j}=1}^{\mathrm{n}} \mathrm{a}_{\mathrm{ij}} \mathrm{x}_{\mathrm{j}}+\left(\mathrm{d}_{\mathrm{i}}^{+}+\mathrm{d}_{\mathrm{i}}^{-}\right)=\mathrm{b}_{\mathrm{i}}$

$$
\begin{gathered}
\mathrm{x}_{\mathrm{j}}, \mathrm{d}_{\mathrm{i}}{ }^{+}, \mathrm{d}_{\mathrm{i}}^{-}>=0 \\
\mathrm{i}=1 \ldots \mathrm{m} \\
\mathrm{j}=1 \ldots \mathrm{n}
\end{gathered}
$$

\section{Uygulama}

Savunma alanında kullanılan Füze sistemleri bir anlamda uçan insansız hava aracı olma özelliği taşımaktadır. $\mathrm{Bu}$ denli sistemlerin stoklarda bekletilip eğitim, tatbikat veya sadece bir tehdit esnasında düşmana karşı anlık kullanılmasından dolayı sistem bileşenlerinin füze ömrü boyunca kusursuz bir şekilde çalışması önem arz etmektedir. Elbette bu kusursuzluk yapilan tasarımın tanımlanan sınırlar içerisinde üretilmesi ile söz konusu olmaktadır. Sistemlerde kullanılan bileşenlerin ham malzemeleri nitelikli malzemeler olup çeşitli ülkelerden tedarik edilmektedir. $\mathrm{Bu}$ malzemeler çeşitlerine göre nerede kullanılacağının bilgisi üretici ülke tarafından sorgulanmakta olup belirli kisıtlar altında temin edilmektedir. Yapilacak işlere ait özelliklerin bu denli yüksek olması bir sonraki adım olan üretim kısmında kısıtlamaktadır. Üretimi yapacak firmalar sadece nitelikli makine, insan gücü ve teknolojiye sahip olmakla kalmayı, ürüne ait izlenebilirlik ve gizlilik gibi faaliyetlerde beraberinde çalıştırıyor olması son derece önemli olmaktadır. Buda yine üreticinin iyi bir kalite sistemine sahip olduğu anlamına gelmektedir. $\mathrm{Bu}$ tarzda işi yönetecek tedarikçi sayısının sınırlı 
olması nedeniyle bu kapsamda değerlendirilecek ürünler kritik olup savunma sektörü kapsamında yapılan çalışmalar stratejik bir öneme sahiptir.

$\mathrm{Bu}$ doğrultuda TS firması bünyesinde yürütülmekte olan projeler kapsamında üretim ihtiyaçları meydana gelmiştir. Bu kritik mekanik bileşenlerin üretimi için ülkemiz için stratejik bir hedef olan \%100 yerli üretim önem arz etmektedir. Yapılması planlanan üretimler için havacılık ve savunma sektörlerinde faaliyet gösteren firmalarla çeşitli projelerde çalışmalar başlatılmıştır. $\mathrm{Bu}$ projelerde alt yüklenici konumunda hizmet verecek KOBİ'nin seçimi ana yüklenici konumundaki TS Firmas1 için kritik öneme sahiptir. Güvenilir tedarikçilerle, istenilen kalite standardında çalışmak ve projeyi sorunsuz yürütebilmek için titiz bir tedarikçi seçimi çalışması yürütülmüştür. Savunma sistemleri projeleri için ülkemizde üretilmesi sağlanarak, millileştirilmesi amaçlanan nitelikli parçaların ileri talaşlı imalat yöntemleriyle üretimini gerçekleştirebilecek bir alt yüklenicinin seçiminin yapılması problemin temelini oluşturmaktadır. Belirli kriterler çerçevesinde parçanın üretilmesi için tedarikçi seçimi önem arz etmektedir. Problem aşağıdaki adımlar çerçevesinde anlatılmıştır.

\section{Adım 1. Problemin Tanımlanması}

Füze sistemlerinde kullanılan mekanik bileşenler, çeşitli ham malzemelere sahip kompleks geometrilerde parçalardır. $\mathrm{Bu}$ parçalara ait ham malzemelerin hemen hemen \%100 ü yurtdış1 alımı olup bunların \%50 civarı ise özel izinlere tabii olarak temin edilmesinden dolay1 kritik pozisyondadırlar. $\mathrm{Bu}$ malzemelerin nihai ürüne dönüşmesinde meydana gelebilecek herhangi bir hata maddi bir zarara yol açacağı gibi tekrar malzeme alım sürecinde başlamasına sebep olacaktır. Yine sistemde kullanılan ürünlerin sertlik gibi değerlerinin yüksek olması üretim sürecinde bir baskı oluşturmaktadır. $\mathrm{Bu}$ sebeplerden dolayı ürünlerin üretimi için sistemli bir çalışmanın yapılması gerekmektedir. Ayrıca yapılan işin doğrulanması, izlenebilirlik, paketleme ve nakliye gibi konularda dikkat edilmesi gerekmektedir. Bu kapsamda işin sağlıklı bir şekilde yapılıp teslimatını gerçekleştirip, yönetecek tedarikçi sayısının sınırlı olması nedeniyle bu ürün, kritik bir üründür.

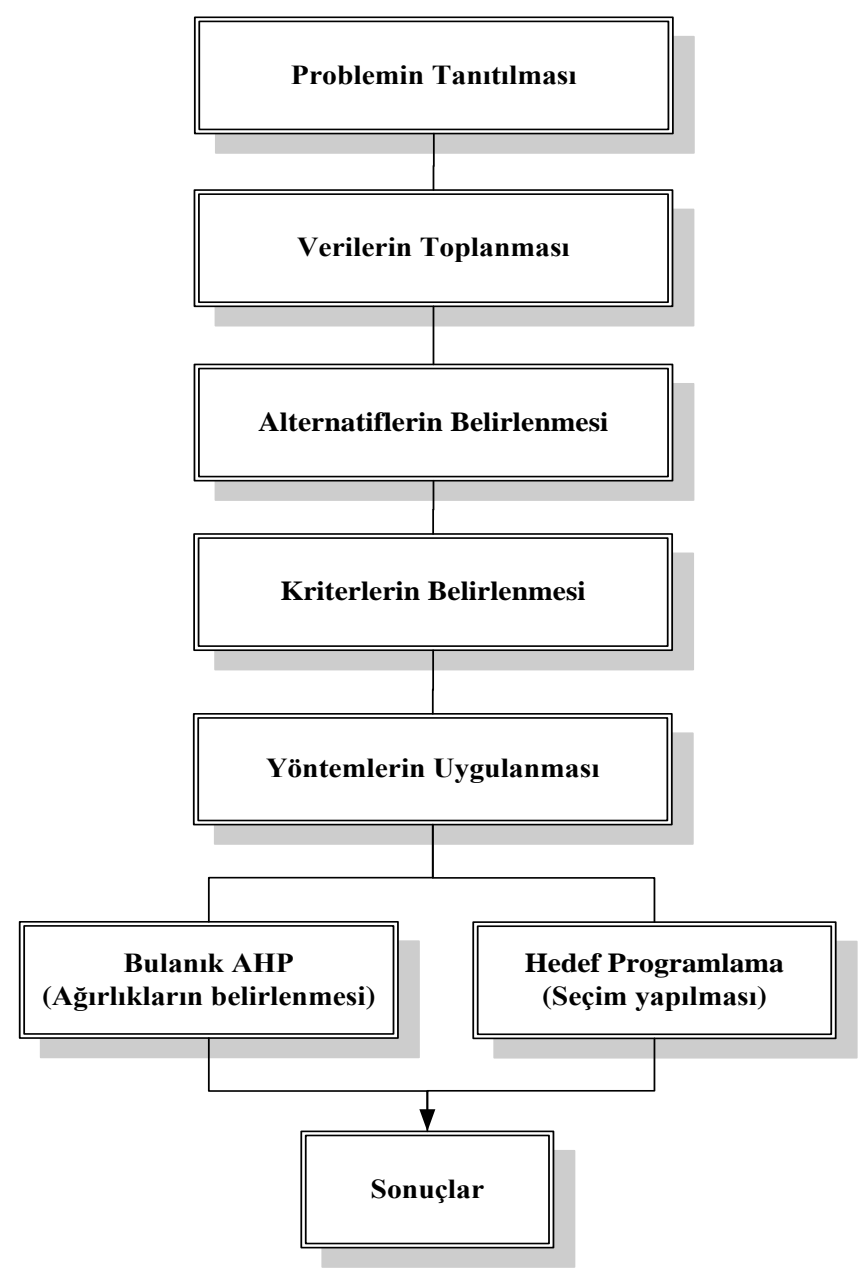

Şekil 1. Problemin Akış Şeması

\section{Adım 2. Verilerin Toplanması}

Savunma ve havacılıkta yapılan çalışmalar doğrultusunda geliştirilen sistemlerin emniyet faktörlerinin yüksek olması ve hata paylarının insan hayatına sebep olması açısından sıfır olarak nitelendirilmesi sistem bileşenlerini de oldukça önemli hale getirmektedir. Bu kapsamda mekanik bileșenlerin üretimi için kullanılacak alt yükleniciler detaylı olarak irdelenmektedir. Seçim yapılan firmalar havacılık ve savunma sektörüne en az 5 y1l üretim hizmeti vermiş, kalite sistemini etkin bir şekilde kullanan AS9100 havacılık kalite belgesine sahip, nitelikli insan gücüne sahip (ortalama 15 personel), her yıl ana yükleniciler tarafindan denetlenip kalite puanı olarak (100 üzerinden) 90 ve üzeri alan firmalar incelenmiştir. $\mathrm{Bu}$ bilgiler satın alma personelleri tarafindan firmaların web siteleri ve birebir görüşmeler sonucunda edinilmiştir.

\section{Adım 3. Alternatiflerin Belirlenmesi}

Seçimi yapacak firmanın sektör olarak hava savunma sanayii alanına hizmet vermesinden dolayı gizlilik, kalite ve referanslar alternatiflerin 
seçilmesi için önem arz etmektedir. Bu seçimin yapılması için TS bünyesinde satın alma biriminden 2 kişi ve üretim biriminden 2 kişi olmak üzere ortalama 10 yıl tecrübeli 4 uzman personel tarafından bir ekip oluşturulmuştur. Geçmiş 5 yıl baz alınarak Türkiye genelinde firmalar taranmıştır. Tarama işlemi kısıtları; havacılık ve savunma sektöründe en az 1 adet referans, an az 1 y1l once alınmış AS9100 kalite belgesi, milli tesis güvenlik belgesine sahip olunması, 5 adet ve üzeri olmak üzere çok eksenli bilgisayar destekli makinelere sahip olunması, işin doğrulanması için en az 1 adet bilgisayar destekli ölçüm cihazına sahip olunması ve işlerin üretim programlarının hazırlanması için en az 1 adet programlama mühendisi, üretilmesi için ise her tezgahta 1 kişi olmak üzere yeterli insan gücünün olması gerekmektedir. Bu şartlara uyan firmalar arasından seçim yapılması hedeflenmektedir.

Uzman heyet tarafından yapılan bu çalışma sonucunda yapılması beklenen mekanik parçaların üretimi için 5 adet tedarikçi bu kriterleri yerine getirmek için uygun bulunmuştur. $\mathrm{Bu}$ firmalar aşağıda gösterildiği gibi kodlanmıştır;

Tedarikçi-1 (T1), *Tedarikçi-2 (T2), Tedarikçi3 (T3), Tedarikçi-4 (T4), Tedarikçi-5 (T5) olmak üzere 5 tanedir.

\section{Adım 4. Kriterlerin Belirlenmesi}

Kriter satın alma biriminde çalışan ve bu konuda 10 yıl tecrübeli 4 personelin ortak görüşü dikkate alınarak belirlenmiştir. Bu kriterler;

- Kalite (KA): Firmanın Havacılık ve Savunma kalite sistemi gereksinimlerine uygun faaliyet gerçekleştiren, ISO 9001:2008, AS9100 ve tesis güvenlik belgesine sahip, Ürünün firmanın istediği kalite düzeyinde, hata oranı düşük ve güvenilir olmasını ifade eder.

- Maliyet (MA): Tedarik edilen ürünün toplam maliyetini (üretim, yüzey işlemeleri, paketleme ve nakliye) ifade eder.

- Tedarik Süresi (TS): Siparişi verilen ürünün firmanın istediği zamanda teslim edilmesini ifade eder.

- İnsan Gücü (İG): Sipariş kapsamındaki ürünlerin üretimini yapacak olan firmada yeteri kadar insan (teknik, idari vb.) gücünün olmasını ifade eder.

- Teknoloji (TE): Yapılacak olan işe uygun makine, cihaz, yazılım ve iletișim ağının olduğunu ifade eder.

\section{Adım 5. Yöntemlerin Uygulanması}

$\mathrm{Bu}$ kısımda iki farklı yöntem uygulanacaktır. Birinci yöntem BAHP'nin uygulanmas1, ikinci yöntem ise Hedef Programlama yöntemidir. BAHP yönteminde işlem kolaylığı açısından üçgen bulanık sayılar kullanılmıştır.

\subsection{BAHP Uygulanması}

Uygulamada yapılacak hesaplamalar 4.2. deki basamaklar izlenmek koşulu ile aşağıdaki gibi yapılmıştır.

\subsubsection{Hiyerarşinin oluşturulması}

Sürecin hiyerarşi modeli sırasıyla amaç, kriterler ve alternatifler olarak Şekil 2.'de gösterilmiştir.

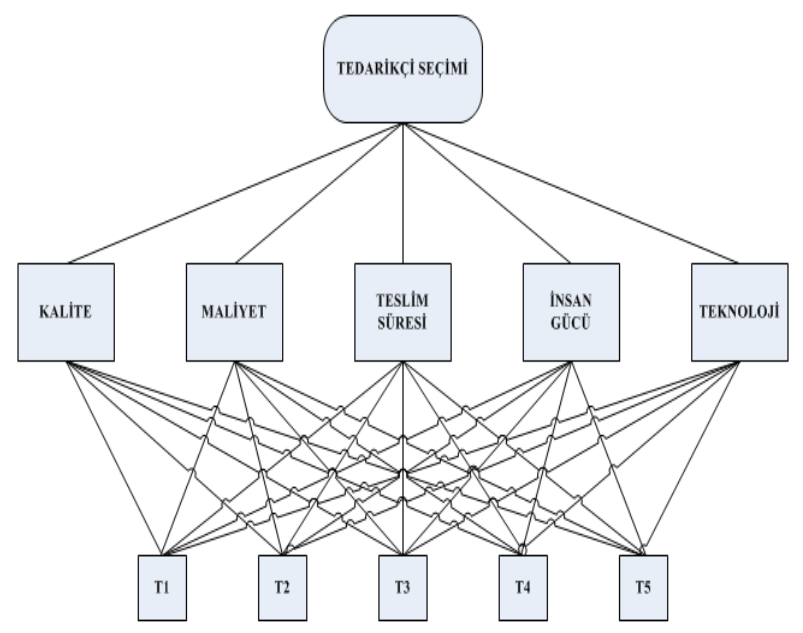

Şekil 2. Tedarikçi seçiminin hiyerarşi modeli

\subsection{2. İkili karşılaştırma matrislerinin oluşturulması}

$\mathrm{Bu}$ aşamada kriterler için ikili karşılaştırma matrisi oluşturulmuştur. $\mathrm{Bu}$ belirlenen değerler en az 10 y1l tecrübeli 2 adet satın alma personeli ve 1 adet üretim mühendisi görüşleri dikkate alarak ortak karar olarak belirlenmiștir. Uygulamada 5 kriter olduğundan $5 \times 5$ lik bir tablo yazılacaktır. Tablodaki değerler üçgen bulanık sayılara göre oluşturulmuştur. Tablo 2.'de ikili karşılaştırma matrisi verilmiştir.

Tablo 2.'de belirtilen değerlere göre sentez değerleri genişletilmiş analiz yöntemine göre hesaplanmıştır. Hesaplamalarda MS Excel programı kullanılmıştır. 
Kriterlere ait sentez değerleri denklem 4.3'e göre hesaplanmıştır.

$$
\begin{aligned}
& \mathrm{SK} 1=(0,1542, \quad 0,3478, \quad 0,6923) \\
& \mathrm{SK} 2=(0,1199,0,3014, \quad 0,6264) \\
& \text { SK3 }=(0,1085,0,2210, \quad 0,4399) \\
& \text { SK4 }=(0,0742, \quad 0,0665, \quad 0,0838)
\end{aligned}
$$

$$
\text { SK5 }=(0,0628, \quad 0,0232, \quad 0,0819)
$$

Sentez değerlerinin olabilirlik dereceleri denklem 4.6 ve 4.7 'e göre hesaplanmıștır.

$\min \mathrm{V}(\mathrm{SK} 1 \geq \mathrm{SK} 2, \mathrm{SK} 3, \mathrm{SK} 4, \mathrm{SK} 5)=1.0000$

$\min \mathrm{V}(\mathrm{SK} 2 \geq \mathrm{SK} 1, \mathrm{SK} 3, \mathrm{SK} 4, \mathrm{SK} 5)=0.9106$

\begin{tabular}{|c|c|c|c|c|c|c|c|c|c|c|c|c|c|}
\hline Kriterler & \multicolumn{4}{|c|}{ KA } & \multicolumn{2}{|l|}{ MA } & \multicolumn{3}{|c|}{ TS } & \multicolumn{2}{|c|}{ İG } & \multicolumn{2}{|c|}{ TE } \\
\hline $\mathbf{K A}$ & 1 & 1 & 1 & 1 & 1 & 1 & 3 & 5 & 7 & & & & 7 \\
\hline MA & 1 & 1 & 1 & 1 & 1 & 1 & 1 & 3 & 5 & ? & & & 5 \\
\hline TS & 0,33 & 0,20 & 0,14 & 1 & 0,33 & 0,20 & 1 & 1 & 1 & & & & 7 \\
\hline İG & 1 & 0,33 & 0,20 & 0,33 & 0,20 & 0,14 & 1 & 0,33 & 0,20 & & & & 1 \\
\hline TE & 0,33 & 0,20 & 0,14 & 1 & 0,33 & 0,20 & 0,33 & 0,20 & 0,14 & & & & 1 \\
\hline
\end{tabular}

$\min \mathrm{V}(\mathrm{SK} 3 \geq \mathrm{SK} 1, \mathrm{SK} 2, \mathrm{SK} 4, \mathrm{SK} 5)=0.6927$

$\min \mathrm{V}(\mathrm{SK} 4 \geq \mathrm{SK} 1, \mathrm{SK} 2, \mathrm{SK} 3, \mathrm{SK} 5)=0.0000$

$\min \mathrm{V}(\mathrm{SK} 5 \geq \mathrm{SK} 1, \mathrm{SK} 2, \mathrm{SK} 3, \mathrm{SK} 4)=0.0000$

Tablo 2. Kriterlerin ikili karşılaştırmalar matrisi

Bu sonuçlar kullanılarak W' ağırlıklar vektörü yazılmıştır.

$$
\mathrm{W}^{\prime}=(1.0000,0.9106,0.6927,0,0)^{\mathrm{T}}
$$

W' ağırlıklar vektörüne normalizasyon işlemi uygulanarak, normalize edilmiş ağırlıklar vektörü yazılmıştır.

$\mathrm{W}=(0.3841,0.3498,0.2661,0.0000,0.0000)^{\mathrm{T}}$

Tablo 3. Kriterlerin ağırlıkları

\begin{tabular}{l|lllll}
\hline Kalite & Maliyet & $\begin{array}{l}\text { Tedarik } \\
\text { süresi }\end{array}$ & $\begin{array}{l}\text { İnsan } \\
\text { gücü }\end{array}$ & Teknoloji \\
\hline \multirow{2}{*}{} & & & & & \\
\hline & & & & & \\
\hline
\end{tabular}

5.1.3. Alternatiflerin kriterlere göre ikili karşılaştırılma matrisi ve ağırlıkların hesaplanması

Uzmanlar tarafindan belirlenen 5 alternatif tedarikçi için, uzman satın alma personeline başvurulmuş ve her bir kritere göre ikili karşılaştırmalar matrislerinin elemanları belirlenmiştir Tablo 4. 
5.1.3.1. Kalite kriterine göre alternatiflerin değerlendirilmesi

Kalite kriterine göre alternatiflere ait sentez değerleri;

$\begin{array}{llll}\text { SK1 } & 0,1755 & 0,4315 & 0,8099 \\ \text { SK2 } & 0,0689 & 0,1404 & 0,2638 \\ \text { SK3 } & 0,1755 & 0,2623 & 0,3952 \\ \text { SK4 } & 0,0845 & 0,0728 & 0,0824 \\ \text { SK5 } & 0,0975 & 0,0254 & 0,1102\end{array}$

Sentez değerlerinin olabilirlik dereceleri;

$\min \mathrm{V}(\mathrm{SK} 1 \geq \mathrm{SK} 2, \mathrm{SK} 3, \mathrm{SK} 4, \mathrm{SK} 5)=1.0000$

$\min \mathrm{V}(\mathrm{SK} 2 \geq \mathrm{SK} 1, \mathrm{SK} 3, \mathrm{SK} 4, \mathrm{SK} 5)=0.2328$

$\min \mathrm{V}(\mathrm{SK} 3 \geq \mathrm{SK} 1, \mathrm{SK} 2, \mathrm{SK} 4, \mathrm{SK} 5)=0.5650$

$\min \mathrm{V}(\mathrm{SK} 4 \geq \mathrm{SK} 1, \mathrm{SK} 2, \mathrm{SK} 3, \mathrm{SK} 5)=0.0000$

$\min \mathrm{V}(\mathrm{SK} 5 \geq \mathrm{SK} 1, \mathrm{SK} 2, \mathrm{SK} 3, \mathrm{SK} 4)=0.0000$

Bu sonuçlar kullanılarak W' ağırlıklar vektörü yazılmıştır.

$\mathrm{W}^{\prime}=(1.0000,0.2328,0.5650,0.0000,0.0000)^{\mathrm{T}}$

W' ağırlıklar vektörüne normalizasyon işlemi uygulanarak, normalize edilmiş ağırlıklar vektörü yazılmıştır.

$$
\mathrm{W}=(0.5562,0.1295,0.3143,0.0000,0.0000)^{\mathrm{T}}
$$

Tablo 4. Alternatiflerin kalite kriterine göre ikili karşılaştırmalar matrisi

\begin{tabular}{l|lll|lll|llll|lll|lll} 
Alternatif & \multicolumn{4}{c}{ T1 } & \multicolumn{4}{c}{ T2 } & \multicolumn{9}{c}{ T3 } & \multicolumn{3}{c}{ T4 } & \multicolumn{3}{c}{ T5 } \\
\hline T1 & 1 & 1 & 1 & 3 & 5 & 7 & 1 & 3 & 5 & 3 & 5 & 7 & 1 & 3 & 5 \\
$\mathbf{T 2}$ & 0,33 & 0,20 & 0,14 & 1 & 1 & 1 & 0,20 & 0,33 & 1 & 1 & 3 & 5 & 1 & 1 & 1 \\
$\mathbf{T 3}$ & 1 & 0,33 & 0,20 & 5 & 3 & 1 & 1 & 1 & 1 & 1 & 3 & 5 & 1 & 3 & 5 \\
$\mathbf{T 4}$ & 0,33 & 0,20 & 0,14 & 1 & 0,33 & 0,20 & 1 & 0,33 & 0,20 & 1 & 1 & 1 & 1 & 1 & 1 \\
$\mathbf{T 5}$ & 1 & 0,33 & 0,20 & 1 & 1 & 1 & 1 & 0,33 & 0,20 & 1 & 1 & 1 & 1 & 1 & 1 \\
\hline
\end{tabular}

Tablo 5. Kalite kriterine göre ağırlıkları

\begin{tabular}{|c|c|c|c|c|c|}
\hline 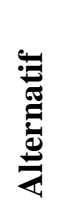 & $\mathbf{T 1}$ & $\mathbf{T} 2$ & T3 & T4 & T5 \\
\hline بِ & 0.5562 & 0.1295 & 0.3143 & 0.0000 & 0.0000 \\
\hline
\end{tabular}

\subsubsection{Maliyet kriterine göre alternatiflerin değerlendirilmesi}

Maliyet kriterine göre alternatiflere ait sentez değerleri;

$\begin{array}{llll}\text { SK1 } & 0,1661 & 0,3100 & 0,5038 \\ \text { SK2 } & 0,1661 & 0,3100 & 0,5038 \\ \text { SK3 } & 0,1359 & 0,1763 & 0,2735 \\ \text { SK4 } & 0,1359 & 0,1763 & 0,2735 \\ \text { SK5 } & 0,0254 & 0,0182 & 0,0347\end{array}$


Sentez değerlerinin olabilirlik dereceleri; $\min \mathrm{V}(\mathrm{SK} 1 \geq \mathrm{SK} 2, \mathrm{SK} 3, \mathrm{SK} 4, \mathrm{SK} 5)=1.0000$ $\min \mathrm{V}(\mathrm{SK} 2 \geq \mathrm{SK} 1, \mathrm{SK} 3, \mathrm{SK} 4, \mathrm{SK} 5)=1.0000$ $\min \mathrm{V}(\mathrm{SK} 3 \geq \mathrm{SK} 1, \mathrm{SK} 2, \mathrm{SK} 4, \mathrm{SK} 5)=0.4455$ $\min \mathrm{V}(\mathrm{SK} 4 \geq \mathrm{SK} 1, \mathrm{SK} 2, \mathrm{SK} 3, \mathrm{SK} 5)=0.4455$ $\min \mathrm{V}(\mathrm{SK} 5 \geq \mathrm{SK} 1, \mathrm{SK} 2, \mathrm{SK} 3, \mathrm{SK} 4)=0.0000$
Bu sonuçlar kullanılarak $\mathrm{W}^{\prime}$ ağırlıklar vektörü yazılmıştır.

$\mathrm{W}^{\prime}=(1.0000,1.0000,0.4455,0.4455,0.0000)^{\mathrm{T}}$

W' ağırlıklar vektörüne normalizasyon işlemi uygulanarak, normalize edilmiş ağırlıklar vektörü yazılmıştır.

$$
\mathrm{W}=(0.3459,0.3459,0.1541,0.1541,0.0000)^{\mathrm{T}}
$$

Tablo 6. Alternatiflerin Maliyet kriterine göre ikili karşılaştırmalar matrisi

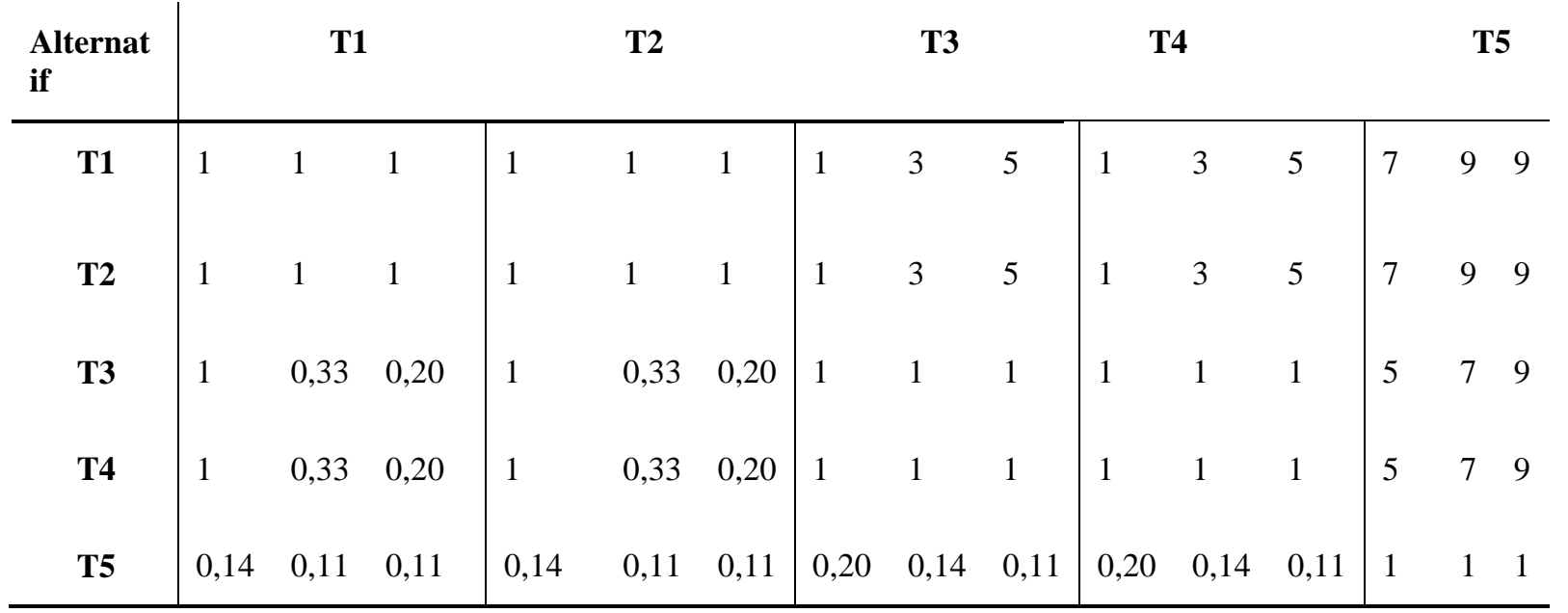

Tablo 7. Maliyet kriterine göre ağırlıkları

\begin{tabular}{c|ccccc}
\hline Alternatifler & T1 & T2 & T3 & T4 & T5 \\
\hline A ğırlıklar & 0.3459 & 0.3459 & 0.1541 & 0.1541 & 0.0000 \\
\hline
\end{tabular}

5.1.3.3. Teslim Süresi kriterine göre alternatiflerin değerlendirilmesi

Teslim Süresi kriterine göre alternatiflere ait sentez değerleri;

$\begin{array}{llll}\text { SK1 } & 0,2499 & 0,4851 & 0,7672 \\ \text { SK2 } & 0,0500 & 0,0649 & 0,1088 \\ \text { SK3 } & 0,1730 & 0,2387 & 0,3228 \\ \text { SK4 } & 0,1730 & 0,1309 & 0,0899 \\ \text { SK5 } & 0,0807 & 0,0231 & 0,0876\end{array}$

Sentez değerlerinin olabilirlik dereceleri;

$\min \mathrm{V}(\mathrm{SK} 1 \geq \mathrm{SK} 2, \mathrm{SK} 3, \mathrm{SK} 4, \mathrm{SK} 5)=1.0000$

$\min \mathrm{V}(\mathrm{SK} 2 \geq \mathrm{SK} 1, \mathrm{SK} 3, \mathrm{SK} 4, \mathrm{SK} 5)=0.0000$

$\min \mathrm{V}(\mathrm{SK} 3 \geq \mathrm{SK} 1, \mathrm{SK} 2, \mathrm{SK} 4, \mathrm{SK} 5)=0.2282$

$\min \mathrm{V}(\mathrm{SK} 4 \geq \mathrm{SK} 1, \mathrm{SK} 2, \mathrm{SK} 3, \mathrm{SK} 5)=0.0000$

$\min \mathrm{V}(\mathrm{SK} 5 \geq \mathrm{SK} 1, \mathrm{SK} 2, \mathrm{SK} 3, \mathrm{SK} 4)=0.0000$

$\mathrm{Bu}$ sonuçlar kullanılarak W' ağırlıklar vektörü yazılmıştır.

$\mathrm{W}^{\prime}=(1.0000,0.0000,0.2282,0.0000,0.0000)^{\mathrm{T}}$

W' ağırlıklar vektörüne normalizasyon işlemi uygulanarak, normalize edilmiş ağırlıklar vektörü yazılmıştır.

$\mathrm{W}=(0.8142,0.0000,0.1858,0.0000,0.0000)^{\mathrm{T}}$ 
Tablo 8. Alternatiflerin Teslim Süresi kriterine göre ikili karşılaştırmalar matrisi

\begin{tabular}{|c|c|c|c|c|c|c|c|c|c|c|c|c|c|c|c|}
\hline Altern & \multicolumn{4}{|c|}{ T1 } & \multicolumn{3}{|c|}{$\mathbf{T} 2$} & \multicolumn{2}{|c|}{ T3 } & \multicolumn{4}{|c|}{ T4 } & \multicolumn{2}{|c|}{ T5 } \\
\hline T1 & 1 & 1 & 1 & 5 & 7 & 9 & 1 & 3 & 5 & 1 & 3 & 5 & 5 & 7 & 9 \\
\hline $\mathbf{T} 2$ & 0,20 & 0,14 & $\begin{array}{l}0, \\
11\end{array}$ & 1 & 1 & 1 & 0,20 & 0,33 & 1 & 0,20 & 0,33 & 1 & 1 & 1 & 1 \\
\hline T3 & 1 & 0,33 & $\begin{array}{l}0, \\
20\end{array}$ & 5 & 3 & 1 & 1 & 1 & 1 & 1 & 3 & 5 & 1 & 3 & 5 \\
\hline T4 & 1 & 0,33 & $\begin{array}{l}0, \\
20\end{array}$ & 5 & 3 & 1 & 1 & 0,33 & 0,20 & 1 & 1 & 1 & 1 & 1 & 1 \\
\hline T5 & 0,20 & 0,14 & $\begin{array}{l}0, \\
11\end{array}$ & 1 & 1 & 1 & 1 & 0,33 & 0,20 & 1 & 1 & 1 & 1 & 1 & 1 \\
\hline
\end{tabular}

Tablo 9. Teslim Süresi kriterine göre ağırlıkları

\begin{tabular}{c|ccccc}
\hline Alternatifler & T1 & T2 & T3 & T4 & T5 \\
\hline Ağırlıklar & 0.8142 & 0.0000 & 0.1858 & 0.0000 & 0.0000 \\
\hline
\end{tabular}

5.1.3.4. İnsan Gücü kriterine göre alternatiflerin değerlendirilmesi

İnsan Gücü kriterine göre alternatiflere ait sentez değerleri;

$\begin{array}{llll}\text { SK1 } & 0,0439 & 0,0438 & 0,0513 \\ \text { SK2 } & 0,3658 & 0,3731 & 0,3774 \\ \text { SK3 } & 0,1324 & 0,1217 & 0,1104 \\ \text { SK4 } & 0,0600 & 0,0438 & 0,0379 \\ \text { SK5 } & 0,5976 & 0,0167 & 0,2566\end{array}$

Sentez değerlerinin olabilirlik dereceleri; $\min \mathrm{V}(\mathrm{SK} 1 \geq \mathrm{SK} 2, \mathrm{SK} 3, \mathrm{SK} 4, \mathrm{SK} 5)=0.0000$ $\min \mathrm{V}(\mathrm{SK} 2 \geq \mathrm{SK} 1, \mathrm{SK} 3, \mathrm{SK} 4, \mathrm{SK} 5)=1.0000$ $\min \mathrm{V}(\mathrm{SK} 3 \geq \mathrm{SK} 1, \mathrm{SK} 2, \mathrm{SK} 4, \mathrm{SK} 5)=0.0000$ $\min \mathrm{V}(\mathrm{SK} 4 \geq \mathrm{SK} 1, \mathrm{SK} 2, \mathrm{SK} 3, \mathrm{SK} 5)=0.0000$ $\min \mathrm{V}(\mathrm{SK} 5 \geq \mathrm{SK} 1, \mathrm{SK} 2, \mathrm{SK} 3, \mathrm{SK} 4)=0.0000$

$\mathrm{Bu}$ sonuçlar kullanılarak W' ağırlıklar vektörü yazılmıştır.

$$
\mathrm{W}^{\prime}=(0.0000,1.0000,0.0000,0.0000,0.0000)^{\mathrm{T}}
$$

W' ağırlıklar vektörüne normalizasyon işlemi uygulanarak, normalize edilmiş ağırlıklar vektörü yazılmıştır.

$$
\mathrm{W}=(0.0000,1.0000,0.0000,0.0000,0.0000)^{\mathrm{T}}
$$


Tablo 10. Alternatiflerin İnsan Gücü kriterine göre ikili karşılaştırmalar matrisi

\begin{tabular}{c|ccc|ccc|cccc|ccc|ccc} 
Alternatifler & \multicolumn{4}{|c}{ T1 } & \multicolumn{4}{c}{ T2 } & \multicolumn{1}{c}{ T3 } & \multicolumn{1}{c}{ T4 } \\
\hline T1 & 1 & 1 & 1 & 0,11 & 0,14 & 0,20 & 0,20 & 0,33 & 1 & 1 & 1 & 1 & 0,11 & 0,14 & 0,20 \\
T2 & 9 & 7 & 5 & 1 & 1 & 1 & 5 & 7 & 9 & 5 & 7 & 9 & 0,20 & 0,33 & 1 \\
T3 & 5 & 3 & 1 & 0,20 & 0,14 & 0,11 & 1 & 1 & 1 & 1 & 3 & 5 & 0,11 & 0,14 & 0,2 \\
T4 & 1 & 1 & 1 & 0,20 & 0,14 & 0,11 & 1 & 0,33 & 0,20 & 1 & 1 & 1 & 0,11 & 0,14 & 0,20 \\
T5 & 9 & 7 & 5 & 5 & 3 & 1 & 9 & 7 & 5 & 9 & 7 & 5 & 1 & 1 & 1 \\
\hline
\end{tabular}

Tablo 11. İnsan Gücü kriterine göre ağırlıkları

\begin{tabular}{c|ccccc}
\hline Alternatifler & T1 & T2 & T3 & T4 & T5 \\
\hline A ğırlıklar & 0.0000 & 1.0000 & 0.0000 & 0.0000 & 0.0000 \\
\hline
\end{tabular}

\subsubsection{Teknoloji kriterine göre alternatiflerin değerlendirilmesi}

İnsan Gücü kriterine göre alternatiflere ait sentez değerleri;

$\begin{array}{llll}\text { SK1 } & 0,0950 & 0,1925 & 0,2849 \\ \text { SK2 } & 0,0950 & 0,1925 & 0,2849 \\ \text { SK3 } & 0,0930 & 0,0649 & 0,0570 \\ \text { SK4 } & 0,0930 & 0,0649 & 0,0570 \\ \text { SK5 } & 0,6561 & 0,0231 & 0,2849\end{array}$

Sentez değerlerinin olabilirlik dereceleri; $\min \mathrm{V}(\mathrm{SK} 1 \geq \mathrm{SK} 2, \mathrm{SK} 3, \mathrm{SK} 4, \mathrm{SK} 5)=1.0000$ $\min \mathrm{V}(\mathrm{SK} 2 \geq \mathrm{SK} 1, \mathrm{SK} 3, \mathrm{SK} 4, \mathrm{SK} 5)=1.0000$ $\min \mathrm{V}(\mathrm{SK} 3 \geq \mathrm{SK} 1, \mathrm{SK} 2, \mathrm{SK} 4, \mathrm{SK} 5)=0.0000$ $\min \mathrm{V}(\mathrm{SK} 4 \geq \mathrm{SK} 1, \mathrm{SK} 2, \mathrm{SK} 3, \mathrm{SK} 5)=0.0000$ $\min \mathrm{V}(\mathrm{SK} 5 \geq \mathrm{SK} 1, \mathrm{SK} 2, \mathrm{SK} 3, \mathrm{SK} 4)=0.5285$
Bu sonuçlar kullanılarak W' ağırlıklar vektörü yazılmıştır.

$\mathrm{W}^{\prime}=(1.0000,1.0000,0.0000,0.0000,0.5285)^{\mathrm{T}}$

W' ağırlıklar vektörüne normalizasyon işlemi uygulanarak, normalize edilmiş ağırlıklar vektörü yazılmıştır.

$\mathrm{W}=(0.3955,0.3955,0.0000,0.0000,0.2090)^{\mathrm{T}}$ 
Tablo 12. Alternatiflerin Teknoloji kriterine göre ikili karşılaştırmalar matrisi

\begin{tabular}{|c|c|c|c|c|c|c|c|c|c|c|c|c|c|c|c|}
\hline Alternatif & \multicolumn{3}{|c|}{ T1 } & \multicolumn{3}{|c|}{$\mathbf{T} 2$} & \multicolumn{3}{|c|}{$\mathbf{T 3}$} & \multicolumn{3}{|c|}{ T4 } & \multicolumn{3}{|c|}{ T5 } \\
\hline T1 & 1 & 1 & 1 & 1 & 1 & 1 & 1 & 3 & 5 & 1 & 3 & 5 & 0,20 & 0,33 & 1 \\
\hline $\mathbf{T} 2$ & 1 & 1 & 1 & 1 & 1 & 1 & 1 & 3 & 5 & 1 & 3 & 5 & 0,20 & 0,33 & 1 \\
\hline T3 & 1 & 0,33 & 0,20 & 1 & 0,33 & 0,20 & 1 & 1 & 1 & 1 & 1 & 1 & 0,11 & 0,14 & 0,20 \\
\hline T4 & 1 & 0,33 & 0,20 & 1 & 0,33 & 0,20 & 1 & 1 & 1 & 1 & 1 & 1 & 0,11 & 0,14 & 0,20 \\
\hline T5 & 5 & 3 & 1 & 5 & 3 & 1 & 9 & 7 & 5 & 9 & 7 & 5 & 1 & 1 & 1 \\
\hline
\end{tabular}

Tablo 13. Teknoloji kriterine göre ağırlıkları

\begin{tabular}{c|ccccc}
\hline Alternatifler & T1 & T2 & T3 & T4 & T5 \\
\hline A ğırlıklar & 0.3955 & 0.3955 & 0.0000 & 0.0000 & 0.2090 \\
\hline
\end{tabular}

\subsubsection{Alternatiflerin Değerlendirilmesi}

İkili karşılaştırmalar matrislerinden elde edilen kriter ağırlık vektörleri ve kriterlerin alternatiflere göre bulunan ağırlıkları Tablo 14.'de belirtilmiştir. Kriterlerden elde edilen ağırlıklar ile kriterlerin alternatiflere göre bulunan ağırlıkları çarpılıp toplanmas1 ile alternatiflerin sirlamada kullanılacak önem yüzdeleri elde edilmiştir.

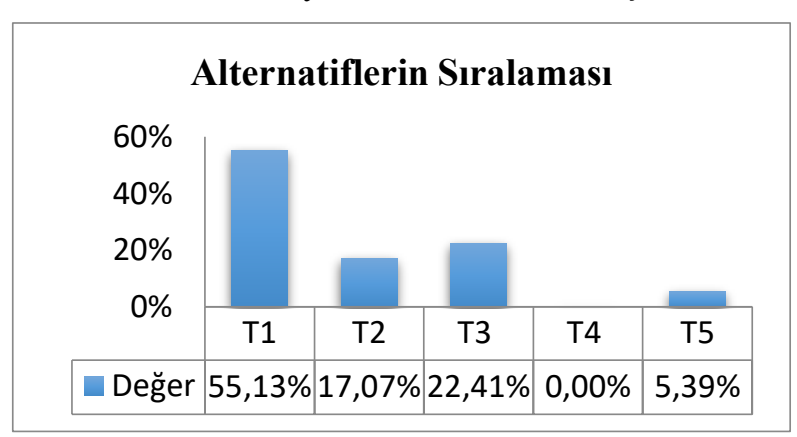

Şekil 3. BAHP Sıralama

Yapılan ikili karşılaştırma ve diğer adımlar sonucunda Şekil 3'de görüldüğü üzere Tedarikçi1'in \% 55.13 ile ilk sırada, Tedarikçi-3'ün 22.41 ile ikinci sırada, Tedarikçi-2'nin 17.07 ile üçüncü sırada yer aldığı, diğerleri ise onu izleyen, Tedarikçi-5 ve Tedarikçi-4 firmalarıdır.

\subsection{Hedef Programala Uygulanması}

Uygulamanın ikinci kısmı olan hedef programlama ile çözüm aşaması, BAHP'de yapılan hesaplama sonucunda bulunan ağırlıklar burada kısıt ve amaç fonksiyona katsayı olarak dâhil edilip iki şekilde hedef programlama modeli kurulacaktır. Burada ağırlıklandırma metodu ile hedef programlama yöntemi ele alınmıştır. Modelin kurulması için belirlenmiş olan bazı kısıtlar aşağıda belirtilmiştir;

* Kapasite Kısıtı: Bir sipariş kapsamında alınacak maksimum miktarı belirtir.

* Üretim Maliyeti Kısıtı: Verilen sipariş kapsamında ödenecek para miktarını belirtir.

*Kaynağında Kalite Kontrol Kısıtı: Ürünlerin kabulünün yapılması için tedarikçi bünyesinde TS personeli tarafindan ikinci kez örnekleme yapılması koşulu ile boyutsal ölçüm ve belgelerin kontrolünün yapılmasını belirtir.

* Teslim Süresi Kısıtı: Ürünlerin taahhüt edilen süre içerisinde teslim edilmesini belirtir. Tedarikçinin ürünleri en geç bu süre zarfında teslim etmesi gerektiği anlamına gelmektedir.

* Fire (hatalı ürün) Oranı Kısıtı: Üretim kapsamında ilgili firma tarafından tedarikçiye verilen bozma oranını belirtir.

* AHP Öncelikleri Kısıtı: İlk yöntem olan AHP yönteminde elde edilen her bir tedarikçinin öncelik skorlarını vermektedir. 
Tablo 14. Kriter ve Alternatiflerin ağırlıklarının hesaplanması

\begin{tabular}{|c|c|c|c|c|c|c|}
\hline $\begin{array}{ll}\text { Ağırlıklar } & \text { Kriterler }\end{array}$ & T1 & $\mathbf{T} 2$ & T3 & T4 & T5 & $\begin{array}{c}\text { Kriter } \\
\text { Ăğırlıkları }\end{array}$ \\
\hline Kalite & 0,5562 & 0,1295 & 0,3143 & 0,0000 & 0,0000 & 0,3841 \\
\hline Maliyet & 0,3459 & 0,3459 & 0,1541 & 0,1541 & 0,0000 & 0,3498 \\
\hline Teslim Süresi & 0,8142 & 0,0000 & 0,1858 & 0,0000 & 0,0000 & 0,2661 \\
\hline İnsan Gücü & 0,0000 & 1,0000 & 0,0000 & 0,0000 & 0,0000 & 0,0000 \\
\hline Teknoloji & 0,3955 & 0,3955 & 0,0000 & 0,0000 & 0,2090 & 0,0000 \\
\hline Alternatiflerin Ăğırlıkları & 0,5513 & 0,1707 & 0,2241 & 0,0000 & $\mathbf{0 , 0 5 3 9}$ & \\
\hline
\end{tabular}

TS söz konusu proje için ihtiyaç duyduğu ürünleri ortalama 60 günlük sürelerle satın alımını gerçekleştirmektedir. $\mathrm{Bu}$ süre içinde alınması planlanan ürün ortalama 200 çeşit olup miktarı ise 300 adettir. Bu 200 çeşit ürün için ürün teslimatına müteakip 30 gün içerisinde ödemelerini yapmaktadır. Bu ödeme miktarı ortalama 200.000 TL'dir. Yapılacak olan bu üretimlerin kalite kontrolünün sağlanması için tedarikçilerin TS personeli tarafindan üretici tesislerinde kalite kontrol işlemleri yapılacaktır. $\mathrm{Bu}$ işlemin süresi üretici tesislerinde bulunan araç gereçler ile doğru orantılıdır. Bu kapsamda Her çeşit üründen 1 tane $\% 100$ kontrol edilmek şartı ile 1'den fazla ürün için Tablo 15' de belirtilen değerler baz alınarak kalite kontroller yapılacaktır. Bu hizmet için ayrılan süre maksimum 20 saattir.
Tablo 15. Kalite kontrol örneklem adetleri

\begin{tabular}{cc}
\hline Ürün Sayısı & Örneklem Sayısı \\
\hline $0-10$ & 1 \\
$10-25$ & 2 \\
$25-75$ & 3 \\
$75-150$ & 4 \\
$150-$ üzeri & 5 \\
\hline
\end{tabular}

Ürünlerin TS'ye tam zamanında teslim edilmesi önem arz etmektedir. Aşırı gecikmeler projede testlerin ötelenmesine ve ekstra gecikme maliyetlerine yol açarken ürünlerin çok erken gelmesinde stok maliyetlerine sebep olmaktadır. Ön görülen gecikmeler maksimum- $/+5$ gün olup firmalar tarafindan ön görülen bu değerler tablo 2'de belirtilmiştir. Ürünlerde meydana gelebilecek hatalar ile ilgili bilgiler tablo 2' de belirtilmiştir. $\mathrm{Bu}$ hatalar üretim esnasında meydana gelebilecek bir durum olacağı gibi taşıma ve diğer türlü sebeplerden kaynaklı durumda olabilir. Tedarikçiler için fire oran $1 \% 2$ olarak belirlenmiştir (100 adet ürün için 2 adet fire hakkı).

Modelin kurulması ile ilgili bilgiler Tablo 16.'da belirtilmiştir. 
Tablo 16. Model için gerekli parametreler

\begin{tabular}{c|ccccc}
\hline \multicolumn{1}{c|}{ Alternatifler } & T1 & T2 & T3 & T4 & T5 \\
Kısıtlar & & & & & \\
\hline Kapasite Kısıtı (60 gün) & 450 & 350 & 250 & 300 & 150 \\
Üretim Maliyeti Kısıtı (TLx1000) & 180 & 170 & 350 & 175 & 255 \\
Kaynağında Kalite Kontrol Kısıtı(Saat) & 18 & 19 & 16 & 18 & 25 \\
Teslim Süresi Kısıtı (maksimum gecikme gün) & 0 & 1 & 4 & 2 & 5 \\
Fire (hatalı ürün) Oranı Kısıtı (100 üründe) & 1 & 1 & 2 & 1 & 2 \\
AHP Öncelikleri Kısıtı (\%) & 0,5513 & 0,1707 & 0,2241 & 0,0539 & 0 \\
\hline
\end{tabular}

Cözüm 1. AHP önceliklerinin kısıt alınarak çözülmesi

\section{Hedefler;}

- Üretim maliyeti kısıtı, diğer kısıtlara oranla 3 kat daha önemlidir.

- Kapasite kısıtı, satın alma maliyeti kısıtını yarısı kadar önemlidir.

- Teslim süresi kısitı, kontrol süresi kısıtından 2 kat daha önemlidir.

- Geriye kalan diğer kısıtların birbiri ile aynı önem derecesine sahip olduğu söylenmiştir.

\section{Parametreler;}

x1: T1 Tedarikçisi,

$\mathbf{x}_{2}:$ : T2 Tedarikçisi,

x3: T3 Tedarikçisi,

$\mathbf{x}_{\mathbf{4}}:$ T4 Tedarikçisi,

xs: T5 Tedarikçisi,

Kapasite K1sit1:

Üretim Maliyeti Kısıt1:

Kaynağında Kalite Kontol Kisıtı:

Teslim Süresi Kısıtı:

Fire (hatalı ürün) Oranı Kısıtı:

AHP Öncelikleri Kısıtı:

$\mathrm{di}^{+}:$i. hedefin pozitif sapma değişkeni

$\mathrm{di}^{-}:$i. hedefin negatif sapma değişkeni

Ör: Kapasite K1sit1 $=\left(d_{1}\right)$

$\mathrm{d}_{1}^{+}$: Kapasite sınırının ne kadar aşıldığını gösterir. $\mathrm{d}_{1^{-}}$: Kapasite sınırının ne kadar altında kalındığını gösterir.

Diğer kısıtlar içinde aynı durum kapasite kısıtında belirtildiği gibidir.

Amaç fonksiyonu:

$\operatorname{Min} \mathrm{Z}=\mathrm{W} 1\left(\mathrm{G}_{1}\right)+\mathrm{W} 2\left(\mathrm{G}_{2}\right)+\mathrm{W} 3\left(\mathrm{G}_{3}\right)+\mathrm{W} 4\left(\mathrm{G}_{4}\right)$ $+\mathrm{W} 5\left(\mathrm{G}_{5}\right)+\mathrm{W} 6\left(\mathrm{G}_{6}\right)$

Min $\mathrm{Z}=1.5\left(\mathrm{~d}_{1}^{-}\right)+3\left(\mathrm{~d}_{2}^{+}\right)+\left(\mathrm{d}_{3}^{+}\right)+2\left(\mathrm{~d}_{4}^{+}\right)+\left(\mathrm{d}_{5}^{+}\right)+$ $\left(\mathrm{d}_{6}{ }^{-}\right)+\left(\mathrm{d}_{6}{ }^{+}\right)$

Kisitlar:

1. Talep Kisitı

$450 \mathrm{x}_{1}+350 \mathrm{x}_{2}+250 \mathrm{x}_{3}+300 \mathrm{x}_{4}+300 \mathrm{x}_{5}+\mathrm{d}_{1}{ }^{-}-$ $\mathrm{d}_{1}{ }^{+}=300$

2. Üretim Maliyeti k1sit1 x1000

$180 \mathrm{x}_{1}+170 \mathrm{x}_{2}+350 \mathrm{x}_{3}+175 \mathrm{x}_{4}+255 \mathrm{x}_{5}+\mathrm{d}_{2}{ }^{-}-$ $\mathrm{d}_{2}{ }^{+}=200$

3. Kalite Kontrol Kisit1

$18 \mathrm{x}_{1}+19 \mathrm{x}_{2}+16 \mathrm{x}_{3}+18 \mathrm{x}_{4}+25 \mathrm{x}_{5}+\mathrm{d}_{3}{ }^{-}-\mathrm{d}_{3}{ }^{+}=20$

4. Teslim Süresi Kısıtı

$0 \mathrm{x}_{1}+1 \mathrm{x}_{2}+4 \mathrm{x}_{3}+2 \mathrm{x}_{4}+5 \mathrm{x}_{5}+\mathrm{d}_{4}^{-}-\mathrm{d}_{4}^{+}=5$

5. Fire Oran 1 Kisit1

$1 \mathrm{x}_{1}+1 \mathrm{x}_{2}+2 \mathrm{x}_{3}+1 \mathrm{x}_{4}+2 \mathrm{x}_{5}+\mathrm{d}_{5}{ }^{-}-\mathrm{d}_{5}{ }^{+}=2$

6. AHP K1sit1

$0,5513 \mathrm{x}_{1}+0,1707 \mathrm{x}_{2}+0,2241 \mathrm{x}_{3}+0,0539 \mathrm{x}_{4}+0$ $\mathrm{x}_{5}+\mathrm{d}_{6}{ }^{-}-\mathrm{d}_{6}{ }^{+}=1$

$\mathrm{xi}=0$ veya $1 \quad \mathrm{i}=1,2,3,4,5$

(Tedarikçiyi seçme ya da seçmeme durumu)

$\mathrm{di}^{-}, \mathrm{di}^{+} \geq 0 \quad \mathrm{i}=1,2,3,4,5$ 
Çözüm 2. AHP önceliklerinin amaç fonksiyonu katsayısı alınarak çözülmesi

Çözüm 1. de alınan parametreler ile aynı olup sadece BAHP'deki öncelikler kısıt değil amaç fonksiyonu katsayısı (hedef) olarak alınmıştır.

Min $\mathrm{Z}=0,5513\left(\mathrm{~d}_{1}^{-}\right)+0,1707\left(\mathrm{~d}_{2}{ }^{+}\right)+0,2241\left(\mathrm{~d}_{3}{ }^{+}\right)$ $+0,0539\left(\mathrm{~d}_{4}^{+}\right)+0\left(\mathrm{~d}_{5}^{+}\right)$

Kisitlar:

\section{Talep Kisit1}

$450 \mathrm{x}_{1}+350 \mathrm{x}_{2}+250 \mathrm{x}_{3}+300 \mathrm{x}_{4}+300 \mathrm{x}_{5}+\mathrm{d}_{1}{ }^{-}-$ $\mathrm{d}_{1}{ }^{+}=300$

2. Üretim Maliyeti k1sit1 $\times 1000$

$180 \mathrm{x}_{1}+170 \mathrm{x}_{2}+350 \mathrm{x}_{3}+175 \mathrm{x}_{4}+255 \mathrm{x}_{5}+\mathrm{d}_{2}{ }^{-}-$ $\mathrm{d}_{2}{ }^{+}=200$

\section{Kalite Kontrol Kisit1}

$18 \mathrm{x}_{1}+19 \mathrm{x}_{2}+16 \mathrm{x}_{3}+18 \mathrm{x}_{4}+25 \mathrm{x}_{5}+\mathrm{d}_{3}{ }^{-}-\mathrm{d}_{3}{ }^{+}=20$

4. Teslim Süresi Kısıt1

$0 \mathrm{x}_{1}+1 \mathrm{x}_{2}+4 \mathrm{x}_{3}+2 \mathrm{x}_{4}+5 \mathrm{x}_{5}+\mathrm{d}_{4}^{-}-\mathrm{d}_{4}^{+}=5$

5. Fire Oran 1 Kisıt

$1 \mathrm{x}_{1}+1 \mathrm{x}_{2}+2 \mathrm{x}_{3}+1 \mathrm{x}_{4}+2 \mathrm{x}_{5}+\mathrm{d}_{5}{ }^{-}-\mathrm{d}_{5}{ }^{+}=2$

$\mathrm{xi}=0$ veya $1 \quad \mathrm{i}=1,2,3,4,5$

(Tedarikçiyi seçme ya da seçmeme durumu)

$\mathrm{di}^{-}, \mathrm{di}^{+} \geq 0 \quad \mathrm{i}=1,2,3,4,5$

Hedef programlama çözümü yapılırken AHP den gelen öncelikler hedef programlamada çözüm 1'de kısıt olarak, çözüm 2'de ise hedef olarak ele alınmıştır. Çıkan sonuçlar Tablo 18'de belirtimiştir. Sonuçlar kıyaslandığında sadece hedef programlamaya göre seçim yapılırsa her iki çözümde de istenilen kriterleri karşıladığı fakat çözüm 2'de maliyetin daha düşük olduğu görülmektedir. Bundan dolayı seçim yapacak kişi çözüm 2 yani AHP önceliklerinin hedef olarak alındığı yöntemi kullanabilir.

Tablo 17'de bu iki modelin uygulanmasiyla kısıtlarda meydana gelecek sapmalar verilmiştir.
Tablo 17. Elde edilen sonuçlara göre sapmalar

\begin{tabular}{|l|l|l|l|l|l|}
\hline \multirow{2}{*}{ Kaynaklar } & \multirow{2}{*}{ Kisitlar } & \multicolumn{2}{|l|}{ HP-1 } & \multicolumn{2}{l|}{ HP-2 } \\
\cline { 3 - 6 } & & N & P & N & P \\
\hline Talep (br) & 300 & - & 150 & - & 50 \\
\hline $\begin{array}{l}\text { Maliyet (tl) } \\
\text { x1000 }\end{array}$ & 200 & 20 & - & 30 & - \\
\hline $\begin{array}{l}\text { Kalite Kontrol } \\
\text { (saat) }\end{array}$ & 20 & 2 & - & 1 & - \\
\hline $\begin{array}{l}\text { Teslim Süresi } \\
\text { (gün) }\end{array}$ & 5 & 5 & - & 4 & - \\
\hline Fire Oranı (br) & 2 & 0.45 & - & 1 & - \\
\hline
\end{tabular}

\section{Adım 6. Sonuçlar}

Uygulanan BAHP ve HP yöntemleri neticesinde BAHP ve HP1'de ayn1, HP2'de ise farkl1 bir tedarikçinin seçildiği görülmektedir. Belirlenmiş kısitlar altında model hedef programlamada gösterildiği gibi kurulmuş olup çözümleme işlemi Lindo 6.1 programına göre yapılmıştır. Beş adet tedarikçi arasından BAHP ve Hedef 1'de T1 tedarikçisinin bu işi yapması, Hedef 2'de ise T2 tedarikçisinin bu işi yapması için uygun olduğu sonucuna varılmıştır.

Yöntemlerde kullanılan değerler satın alma uzmanları ve üretim mühendisleri tarafindan proje isterileri göz önünde bulundurularak belirlenmiştir. Bundan dolayı yapılan değerlendirmeler sonucunda belirlenen tedarikçilerin bu ișin yapılmasında doğru bir seçim olduğu uzmanlar tarafindan mutabık kalınmıştır.

Tablo 18. Sonuçların Karşılaştırılması

\begin{tabular}{l|lll}
\hline & BAHP & HP1 & HP2 \\
Tedarikçi-1 & 1 & 1 & - \\
Tedarikçi-2 & 3 & - & 1 \\
Tedarikçi-3 & 2 & - & - \\
Tedarikçi-4 & 5 & - & - \\
Tedarikçi-5 & 4 & - & - \\
\hline
\end{tabular}




\section{Sonuç}

İş hayatında sıklıkla rastlanan konulardan biri olan tedarikçi seçimi problemleri, çok kriterli karar verme yöntemleri ile ele alınan problemlerden biridir. Tedarikçi seçimi problemlerinin çözümünde; uygun kriterlerin belirlenmesi, etkileşimlerin açık bir şekilde ifade edilmesi ve karşılaştırmaların tutarlı bir biçimde yapılması oldukça kritiktir. Kurum veya kuruluşların yapmak üzere oldukları tedarikçi tercihlerini doğru bir şekilde yapabilmeleri için bilimsel metotların kullanılması önerilmektedir. Aksi halde istenilen kriterlere uygun olmayan özelliklerde tedarikçiler seçilerek, firma projelerinin teslimat performansı veya maliyet etkinliği etkilenebilir.

$\mathrm{Bu}$ çalışmada, ülkemiz hava savunma sanayiine katkı sağlamak amacıyla kurulan ve bu kapsamda Ar-Ge çalışmaları yapan TS Savunma firmasına yönelik bir tedarikçi seçim problemi ele alınmıştır. Yine bu makale kapsamında, çok kriterli karar verme araçlarından BAHP ve Hedef Programlama yöntemleri kullanılarak söz konusu işletme için en uygun tedarikçinin seçilmesi amaçlanmıştır.

Yapılan literatür araştırması neticesinde, birçok sektörde yaygın olarak kullanıldığ 1 tespit edilen kalite, maliyet, teslim süresi, insan gücü ve teknoloji kriterleri ana kriterler olarak belirlenmiştir. Çalışmada, belirtilen yöntemler uygulanarak beş potansiyel tedarikçi firma değerlendirilmiş ve her iki yönteme göre de en iyi firmalar belirlenmiştir. Bu kapsamda, BAHP ve HP yöntemleri uygulaması sonucuna göre Tedarikçi1 'in bu işi yapılmasında uygun olduğu değerlendirilmektedir.

$\mathrm{Bu}$ tarz stratejik ve taktik kararların bilimsel dayanakları olmasına son derece önem gösteren TS Savunma firması, tedarikçi seçimini doğru bir şekilde yaparak arzu edilen yapıda bir tedarikçi ağ 1 kuracak olup tedarik zincirini güçlendirecektir. $\mathrm{Bu}$ çalışmanın devamında, bu yöntemin geliştirilmesi ve şirketin bütün tedarikçi seçimi süreçlerinde kullanımı hedeflenmiştir.

\section{Kaynaklar}

[1] Çakın E, Özdemir, A. "Tedarikçi seçim kararında ANP ve ELECTRE yöntemlerinin kullanılması ve bir uygulama." Afyon Kocatepe Üniversitesi İIBF Dergisi., 15(2), 339-364, 2013.

[2] Toksarı M, Toksarı MD. "Bulanık AHP yaklaşımı kullanılarak hedef pazarın belirlenmesi." ODTÜ Geliştirme Dergisi., 38: 5170, 2011.

[3] Schniederjans MJ, Hoffman, JJ, Sirmans GS. "Using Goal Programming and the Analytic Hierarchy Process in House Selection." Journal of Real Estate Finance and Economics., 11(2), 167-176, 1995.

[4] Ghodsypour SH, O'Brien C. "A decision support system for supplier selection using an integrated analytic hierarchy process and linear programming." Int. J. Production Economics., 56-57: 199-212, 1998.

[5] Badri AM. "Combining the analytic hierarchy process and goal programming for global facility location-allocation problem." Int. J. Production Economics., 62: 237-248, 1999.

[6] Dağdeviren M, Eren T. "Tedarikçi Firma Seçiminde Analitik Hiyerarşi Prosesi ve 0-1 Hedef Programlama Yöntemlerinin Kullanılması." Gazi Üniversitesi MühendislikMimarlık Fakültesi Dergisi., 16(2), 41-52, 2001.

[7] Kağnıcıoğlu CH. "Hedef programlama ve bulanık hedef programlama arasındaki ilişki." Gazi Üniversitesi İktisadi ve İdari Bilimler Fakültesi Dergisi., 7(2), 17-38, 2006.

[8] Reddy AR, Naidu MM, Govindarajulu P. An "Integrated approach of Analytical Hierarchy Process Model and Goal Model (AHP-GP Model) for Selection of Software Architecture." International Journal of Computer Science and Network Security., 7(10), 108-117, 2007.

[9] Öztürk A, Ertuğrul İ, Karakaşoğlu N. "Nakliye firması seçiminde Bulanık AHP ve BTOPSIS 
yöntemlerinin karşılaştırılması.” Marmara Üniversitesi İ.İ.B.İ.F. Dergisi., 25(2), 785-824, 2008.

[10] Girginer N, Kaygısız Z. "İstatistiksel yazılım seçiminde Analitik Hiyerarşi Süreci ve $0-1$ Hedef Programlama yöntemlerinin birlikte kullanımı.” Eskişehir Osmangazi Üniversitesi Sosyal Bilimler Dergisi., 10(1), 211-233, 2009.

[11] Aktepe A, Ersöz S. A Fuzzy "Analytic Hierarchy Process Model for Supplier Selection and A Case Study." International Journal of Research and Development., 3(1), 33-37, 2011.

[12] Kazançoğlu Y, Ada E. "Perakende sektöründe tedarikçi seçiminin Bulanık AHP ile gerçekleştirilmesi." Savunma Bilimleri Dergisi., Kabul Tarihi:08.04.2010.

[13] Karpak B, Kasuganti RR, Kumcu E. "MultiObjective Decision-Making in Supplier Selection: An Application of Visual Interactive Goal Programming." The Journal of Applied Business Research, 15(2), 57-71, 2011.

[14] Junior RLF, Osiro L, Carpinetti LCR. "A comparison between Fuzzy AHP and Fuzzy TOPSIS methods to supplier selection." Applied Soft Computing., 21: 194-209, 2014.

[15] Karimi H, Rezaeinia A. "Supplier selection using revised multi-segment goal programming model." Int $\mathrm{J}$ Adv Manuf Technol. 70: 1227-1234, 2014.

[16] Kannan, D, Jabbour, ABLDS, Jabbour. CJC. "Selecting Green Suppliers Based on GSCM Practices: Using Fuzzy TOPSIS Applied to A Brazilian Electronics Company." European Journ All of Operational Research, 233 (2): 432-447, 2014.

[17] Özder EH, Eren T, Çetin SÖ. "Supllier selecion with TOPSIS and Goal Programming methods: A case study." Journal of Trends in the Development of Machinery and Associated Technology., 19(1), 109-112, 2015.

[18] Kar, AK. A Hybrid Group Decision Support "System for Supplier Selection Using Analytic Hierarchy Process, Fuzzy Set Theory and
Neural Network." Journal of Computational Science, 6: 23-33, 2015.

[19] Jadidi O, Cavalieri S, Zolfaghari S. "An improved multi-choice goal programming approach for supplier selection problems." Applied Mathematical Modelling. 39: 42134222, 2015. [20] Sivrikaya BT, Kaya A, Dursun E, Çebi F. Fuzzy "AHP-Goal Programming approach for a supplier selection problem." Research in Logistics \& Production., 5(3), 271-285, 2015.

[21] Galankashi, MR, Helmi, SA. Hashemzahi, P., "Supplier Selection in Automobile Industry: A Mixed Balanced Scorecard-Fuzzy AHP Approach." Alexandria Engineering Journal, 55 (1): 93-100, 2016.

[22] Özder EH, Eren T. "Çok ölçütlü karar verme yöntemi ve hedef programlama teknikleri ile tedarikçi seçimi." Selçuk Üniversitesi Mühendislik Bilim ve Teknoloji Dergisi., 4(3), 196-207, 2016.

[23] Tavana, M, Fallahpour, A, Caprio DD, Artega, FJS. "A Hybrid Intelligent Fuzzy Predictive Model with Simulation for Supplier Evaluation and Selection." Expert Systems with Applications, 61: 129-144, 2016.

[24] Aydın, Y, Eren, T. "Savunma Sanayii Alt Yüklenici Seçiminde Bulanık Mantık Altında Çok Kriterli Karar Verme ve Hedef Programlama Yöntemlerinin Kullanılması." 37. Yöneylem Araştırması Ve Endüstri Mühendisliği Ulusal Kongresi, Yıldız Teknik Üniversitesi, İstanbul, 87, 2017a.

[25] Aydın, Y, Eren, T. "Savunma Sanayinde Füze Sistemleri İçin Kullanılan Titanyum Ham Malzemeye Sahip Kritik Ürünlerin Üretimi İçin Bulanık AHP-TOPSIS Algoritmaları İle Tedarikçi Seçimi." 2. Uluslararası Savunma Sanayi Sempozyumu, Kırıkkale Üniversitesi, Kırıkkale 816-825, 2017b.

[26] Aydın, Y, Eren, T. "Savunma Sanayinde Stratejik Ürün İçin Çok Kriterli Karar Verme Yöntemleri İle Tedarikçi Seçimi." Ömer Halisdemir Üniversitesi Mühndislik Bilimleri Dergisi, (Basımda), 2018. 
[27] Beil RD. Wiley Encyclopedia of Operations Research and Management Science, 2009.

[28] Vonderembse MA, Tracey M. "The Impact of Supplier Selection Criteria and Supplier Involvement on Manufacturing Performance." Journal of Supply Chain Management., 35(3), 33-39, 1999.

[29] Masson RJ. "User-vendor relationship in the scottish electrnics industry." Internatioanl journal of quality \& reliability management., 3(2), 31-40, 1986.

[30] Bhutta KS, Huq F. "Supplier selection problem: a comparison of the total cost of ownership and analytic hierarchy process approaches.” An International Journal., 7(3), 126-135, 2002.

[31]

http://tusside.tubitak.gov.tr/tr/yontemlerimiz/ Cok-Kriterli-Karar-Verme-Teknikleri， erişim tarihi: 13.05.2017)

[32] Akman G, Atakan A. "Tedarik zinciri yönetiminde bulanık AHP yöntemi kullanılarak tedarikçilerin performansının ölçülmesi: Otomotiv yan sanayiinde bir uygulama." İstanbul Ticaret Üniversitesi Fen Bilimleri Dergisi., 9: 23-46,2006.

[33] Dağdeviren M. "Performans değerlendirme sürecinin Bulanık AHP ile bütünleşik modellenmesi." Mühendislik ve Fen Bilimleri Dergisi Sigma., 25(3), 268-282, 2007.

[34] Zadeh L A. "Fuzzy sets." Information and control., 8(3), 338-353, 1965.

[35] Buckley JJ. "Fuzzy hierarchical analysis." Fuzzy Sets and Systems., 17(3), 233-247, 1985

[36] Özbek A. "Tedarikçi seçiminde çok kriterli karar verme yöntemlerinin kullanılması." Gümüşhane Üniversitesi sosyal bilimler elektronik dergisi., 11: 69-99, 2014.

[37] Chang DY. "Applications of the extent analysis method of fuzzy AHP." European Journal of Operational Research., 95: 649-655, 1996.

[38] Charnes A, Cooper WW, Ferguson R. "Optimal Estimation of Executive
Compensation by Linear Programming." Management Science., 1: 138-151, 1955.

[39] Charnes A, Cooper WW. "Goal programming and multiple objective optimizations." European Journal of Operational Research., 1(1), 39-54, 1977. 